\title{
Cerebellar Projections to the Prefrontal Cortex of the Primate
}

\author{
Frank A. Middleton ${ }^{1}$ and Peter L. Strick ${ }^{1,2,3}$ \\ Departments of ${ }^{1}$ Neurobiology and ${ }^{2}$ Psychiatry, University of Pittsburgh School of Medicine, Pittsburgh, Pennsylvania \\ 15261, and ${ }^{3}$ Department of Veterans Affairs Medical Center, Pittsburgh, Pennsylvania 15240
}

\begin{abstract}
The cerebellum is known to project via the thalamus to multiple motor areas of the cerebral cortex. In this study, we examined the extent and anatomical organization of cerebellar input to multiple regions of prefrontal cortex. We first used conventional retrograde tracers to map the origin of thalamic projections to five prefrontal regions: medial area $9(9 \mathrm{~m})$, lateral area $9(9 \mathrm{l})$, dorsal area $46(46 \mathrm{~d})$, ventral area 46 , and lateral area 12. Only areas $46 \mathrm{~d}, 9 \mathrm{~m}$, and 9 received substantial input from thalamic regions included within the zone of termination of cerebellar efferents. This suggested that these cortical areas were the target of cerebellar output. We tested this possibility using retrograde transneuronal transport of the Mclntyre-B strain of herpes simplex virus type 1 from areas of prefrontal cortex. Neurons labeled by retrograde transneuronal transport of virus were found in the dentate nucleus only after injections into
\end{abstract}

Which cortical areas are the target of cerebellar output? The answer to this question has important implications for concepts about cerebellar function. The traditional view of cerebrocerebellar loops is that they gather information from widespread cortical areas in the frontal, parietal, and temporal lobes (Brodal, 1978; Hartmann-von Monakow et al., 1981; Vilensky and van Hoesen, 1981; Leichnetz et al., 1984; Glickstein et al., 1985; Schmahmann and Pandya, 1997a). The output of cerebellar processing is then thought to be directed at a single cortical area, the primary motor cortex (M1). Thus, cerebrocerebellar circuits are believed to function primarily in the domain of motor control (Evarts and Thach, 1969; Kemp and Powell, 1971; Allen and Tsukahara, 1974; Allen et al., 1978; Brooks and Thach, 1981; Asanuma et al., 1983).

A number of observations have raised doubts about the general applicability of this point of view. From an anatomical perspective, it is now clear that the site of termination of cerebellar efferents is not restricted to only the subdivisions of the ventrolateral thalamus that innervate M1. In fact, the regions of the thalamus that receive cerebellar input are now recognized as a diverse group that innervates many motor and nonmotor areas of the cerebral cortex (Kusama et al., 1971; Kievit and Kuypers, 1972, 1977; Percheron, 1977; Sasaki et al., 1979; Stanton, 1980;

\footnotetext{
Received July 26, 2000; revised Oct. 19, 2000; accepted Oct. 30, 2000.

This work was supported by the Veterans Affairs Medical Research Service and by United States Public Health Service Grants MH11262 (F.A.M.), MH56661 (P.L.S.), and MH48185 (P.L.S.). We thank M. Page for the development of computer programs and W. Burnette, M. Corneille-Evans, S. Fitzpatrick, K. Hughes, and M. O'Malley-Davis for their expert technical assistance. We also thank Drs. D. I. Bernstein (Gamble Institute of Medical Research, Cincinnati, OH), R. D. Dix (Jones Eye Institute, Little Rock, AR), and J. H. LaVail (University of California San Francisco, San Francisco, CA) for supplying HSV1.

Correspondence should be addressed to Dr. Peter L. Strick, Departments of Neurobiology and Psychiatry, University of Pittsburgh, W1640 Biomedical Science Tower, 200 Lothrop Street, Pittsburgh, PA 15261. E-mail: strickp@pitt.edu. Copyright (C) 2001 Society for Neuroscience $0270-6474 / 01 / 210700-13 \$ 15.00 / 0$
}

areas $46 \mathrm{~d}, 9 \mathrm{~m}$, and 91 . The precise location of labeled neurons in the dentate varied with the prefrontal area injected. In addition, the dentate neurons labeled after virus injections into prefrontal areas were located in regions spatially separate from those labeled after virus injections into motor areas of the cerebral cortex. Our observations indicate that the cerebellum influences several areas of prefrontal cortex via the thalamus. Furthermore, separate output channels exist in the dentate to influence motor and cognitive operations. These results provide an anatomical substrate for the cerebellum to be involved in cognitive functions such as planning, working memory, and rule-based learning.

Key words: prefrontal cortex; cerebellum; thalamus; dentate nucleus; transneuronal transport; herpes simplex virus; primate

Kalil, 1981; Miyata and Sasaki, 1983; Schell and Strick, 1984; Goldman-Rakic and Porrino, 1985; Wiesendanger and Wiesendanger, 1985a,b; Matelli et al., 1989; Orioli and Strick, 1989; Darian-Smith et al., 1990; Gonzalo-Ruiz and Leichnetz, 1990; Barbas et al., 1991; Yamamoto et al., 1992; Rouiller et al., 1994; Matelli and Luppino, 1996; Percheron et al., 1996; Sakai et al., 1996). In addition, there is physiological evidence that the activity of neurons in selected regions of the cerebellum is related more to cognitive aspects of performance than to motor function (Kim et al., 1994; Mushiake and Strick, 1995; Gao et al., 1996; for review, see Middleton and Strick, 1997). Furthermore, cerebellar lesions can result in cognitive as well as motor deficits (for review, see Leiner et al., 1986, 1987, 1989, 1991, 1993; Botez et al., 1989; Ivry and Keele, 1989; Schmahmann, 1991; Akshoomoff and Courchesne, 1992; Fiez et al., 1992; Grafman et al., 1992; Schmahmann and Pandya, 1997b; Schmahmann and Sherman, 1998).

Motivated in part by these observations, we decided to examine the extent and topographic organization of cerebellar input to multiple regions of prefrontal cortex. Defining such connections would provide an anatomical substrate for the cerebellum to influence working memory and other aspects of higher executive function. Indeed, in a series of reviews, Leiner et al. (1986, 1987, 1989, 1991, 1993) suggested the existence of a cerebellar projection to higher order areas in the frontal lobe based on the parallel expansion of the dentate nucleus and prefrontal cortex in higher primates. In the present study we used retrograde transneuronal transport of the McIntyre-B strain of herpes simplex virus type 1 (HSV1) to determine whether five specific areas of prefrontal cortex are the target of cerebellar output: medial and lateral area 9 (9m and 9l, respectively), dorsal and ventral area 46 (46d and $46 \mathrm{v}$, respectively), and lateral area 12 (121). We examined these 


\begin{tabular}{|c|c|c|c|c|c|c|}
\hline Area(s) injected & Case & $\begin{array}{l}\text { Tracer } \\
\text { or virus }\end{array}$ & $\begin{array}{l}\text { Concentration }(\% \\
\mathrm{w} / \mathrm{v} \text { or } \mathrm{pfu} / \mathrm{ml})\end{array}$ & $\begin{array}{l}\text { Number of } \\
\text { injections }\end{array}$ & $\begin{array}{l}\text { Vol injected } \\
(\mu \mathrm{l})\end{array}$ & $\begin{array}{l}\text { Survival } \\
\text { time (d) }\end{array}$ \\
\hline \multicolumn{7}{|c|}{$\begin{array}{c}\text { Conventional tracer } \\
\text { experiments }\end{array}$} \\
\hline $9 \mathrm{~m}$ & $\mathrm{~F} 14$ & $\mathrm{RD}$ & $10 \%$ & 17 & 1.7 & 12 \\
\hline 91 & F27L & NY & $1 \%$ & 10 & 2.5 & 5 \\
\hline $46 \mathrm{~d}$ & $\mathrm{~F} 2$ & DY & $2 \%$ & 24 & 2.4 & 7 \\
\hline $46 v$ & $\mathrm{~F} 2$ & FB & $5 \%$ & 35 & 3.5 & 7 \\
\hline 121 & F27R & FB & $5 \%$ & 11 & 2.75 & 5 \\
\hline \multicolumn{7}{|l|}{ Virus experiments } \\
\hline $10 \mathrm{~d}$ & F20 & HSV1 & $1.2 \times 10^{10}$ & 48 & 3.5 & 5 \\
\hline $10 \mathrm{~d}$ & F21R & HSV1 & $1.5 \times 10^{10}$ & 39 & 3.5 & 5 \\
\hline $9 \mathrm{~m}$ & F19 & HSV1 & $8.5 \times 10^{10}$ & 33 & 3.0 & 5 \\
\hline $9 \mathrm{~m}$ & $\mathrm{~F} 25$ & HSV1 & $3.0 \times 10^{9}$ & 25 & 2.4 & 5 \\
\hline 91 & F11L & HSV1 & $1.0 \times 10^{9}$ & 28 & 2.8 & 5 \\
\hline 91 & $\mathrm{~F} 21 \mathrm{~L}$ & HSV1 & $1.5 \times 10^{10}$ & 38 & 3.5 & 5 \\
\hline 46 & $\mathrm{~F} 1$ & HSV1 & $1.1 \times 10^{8}$ & 42 & 2.1 & 5 \\
\hline 46 & F6 & HSV1 & $2.5 \times 10^{8}$ & 59 & 3.0 & 5 \\
\hline 46 & F11R & HSV1 & $1.0 \times 10^{9}$ & 56 & 5.0 & 5 \\
\hline $46 \mathrm{~d}$ & $\mathrm{~F} 24 \mathrm{~L}$ & HSV1 & $1.0 \times 10^{11}$ & 25 & 2.4 & 5 \\
\hline $46 \mathrm{~d}$ & F28L & HSV1 & $3.0 \times 10^{9}$ & 21 & 4.0 & 5 \\
\hline $46 \mathrm{v}$ & F24R & HSV1 & $1.0 \times 10^{11}$ & 23 & 2.3 & 5 \\
\hline $46 v$ & F28R & HSV1 & $3.0 \times 10^{9}$ & 19 & 3.8 & 5 \\
\hline 121 & F12 & HSV1 & $1.0 \times 10^{9}$ & 29 & 2.9 & 5 \\
\hline 121 & $\mathrm{~F} 27 \mathrm{~L}$ & HSV1 & $3.0 \times 10^{9}$ & 17 & 3.4 & 5 \\
\hline
\end{tabular}

cortical areas because studies with conventional tracers provided evidence that they receive some input from regions of the ventrolateral thalamus that are the site of termination of cerebellar efferents. There are two major results of this study. First, we found that the cerebellum projects via the thalamus to portions of areas 9 and 46 in prefrontal cortex. Second, the cerebellar projections to prefrontal cortex originate from dentate regions that are spatially separate from those that influence motor areas of cortex. Thus, separate output channels exist in the dentate to influence motor and cognitive operations.

Parts of this paper have been published previously (Middleton and Strick, 1994, 1996, 1997, 1998, 2000).

\section{MATERIALS AND METHODS}

This report is based on observations from 12 juvenile cebus monkeys (Cebus apella; $1.3-2.4 \mathrm{~kg}$ ) (Table 1). The McIntyre-B strain of HSV1 was injected into different regions of the prefrontal cortex in 13 hemispheres. Fluorescent tracers were injected into comparable regions of cortex in 4 hemispheres. The procedures adopted for this study and the care provided experimental animals conformed to the regulations detailed in the National Institutes of Health Guide for the Care and Use of Laboratory Animals. All protocols were reviewed and approved by the Institutional Animal Care and Use committees. The biosafety precautions taken during these experiments conformed to or exceeded the biosafety level 2 (BSL-2) regulations detailed in Biosafety in Microbiological and Biomedical Laboratories (Health and Human Services publication 93-8395). A detailed description of the procedures for handling virus and virusinfected animals is presented in Strick and Card (1992) and Hoover and Strick (1999).

\section{Surgery}

Twelve hours before surgery, each animal was administered dexamethasone (Decadron, $0.5 \mathrm{mg} / \mathrm{kg}$, i.m.) and restricted from food and water. Approximately $20 \mathrm{~min}$ before initiating anesthesia, animals were pretreated with either atropine sulfate $(0.05 \mathrm{mg} / \mathrm{kg}$, i.m.) or glycopyrrolate $(0.01 \mathrm{mg} / \mathrm{kg}, \mathrm{i} . \mathrm{m}$.). Most of the animals were anesthetized initially with ketamine hydrochloride (Ketalar, 15-20 mg/kg, i.m.), intubated, and maintained under gas anesthesia using a 1:1 mixture of isoflurane (Enflurane) and nitrous oxide $(1.5-2.5 \% ; 1-31 / \mathrm{min})$. Other animals were anesthetized with Telazol (initial dose, $20 \mathrm{mg} / \mathrm{kg}$, i.m.; supplemental dose, $5-7 \mathrm{mg} \cdot \mathrm{kg}^{-1} \cdot \mathrm{hr}^{-1}$, i.m.). In these cases, the analgesic butorphenol (Torbugesic, $0.1-0.4 \mathrm{mg} / \mathrm{kg}$, i.m.) was given every $2-4 \mathrm{hr}$ to reduce the overall amount of Telazol used. After being anesthetized, all animals were administered dexamethasone $(0.5 \mathrm{mg} / \mathrm{kg}$, i.m. $)$ and an antibiotic [cefazolin sodium (Kefzol, $25 \mathrm{mg} / \mathrm{kg}$, i.m.) or ceftriaxone (Rocephin, 75 $\mathrm{mg} / \mathrm{kg}$, i.m.)]. Hydration was maintained using lactated Ringer's solution with $5 \%$ dextrose $(6-10 \mathrm{cc} / \mathrm{hr}$, i.v. $)$, and temperature was maintained with a heating pad. Heart rate, blood oxygen saturation, body temperature, and respiratory depth were continuously monitored during the surgery.

All surgical procedures were conducted using aseptic techniques. Each animal's head was positioned in a stereotaxic frame (Kopf). Ophthalmic ointment was placed in the eyes. One or two large craniotomies were performed over the frontal lobe(s), and the dura was incised and reflected to expose the region of interest. The cortex was kept moist using warmed $\left(37-40^{\circ} \mathrm{C}\right)$ sterile saline throughout the entire procedure.

\section{Injection sites}

Injections of HSV1 or conventional tracers were made at multiple sites within areas 9, 46, and 12 in the prefrontal cortex (see Table 1, Figs. 1, 2). The location of each injection site was based on surface landmarks and their known relationship to the cytoarchitectonic borders of the prefrontal cortex. Injections into the portions of area 46 within the banks of the principal sulcus were further guided by magnetic resonance images of the frontal lobe taken at least 1 week before surgery. Injections were made with a $5 \mu$ l Hamilton syringe, using a $28-32$ gauge needle. For injections into cortical gyri, the needle was oriented perpendicular to the cortical surface, and tracer was injected $\sim 1.5 \mathrm{~mm}$ below the cortical surface. For injections into the banks of the principal sulcus or into medial area 9, the needle was oriented parallel to the cortical surface, and tracer was injected at multiple depths $(1.5-6.0 \mathrm{~mm})$ below the surface. After each injection, the microsyringe was left in place for 1-2 min. When the injections were completed, the dura and bone flap were replaced, and the incision was closed in anatomical layers. 

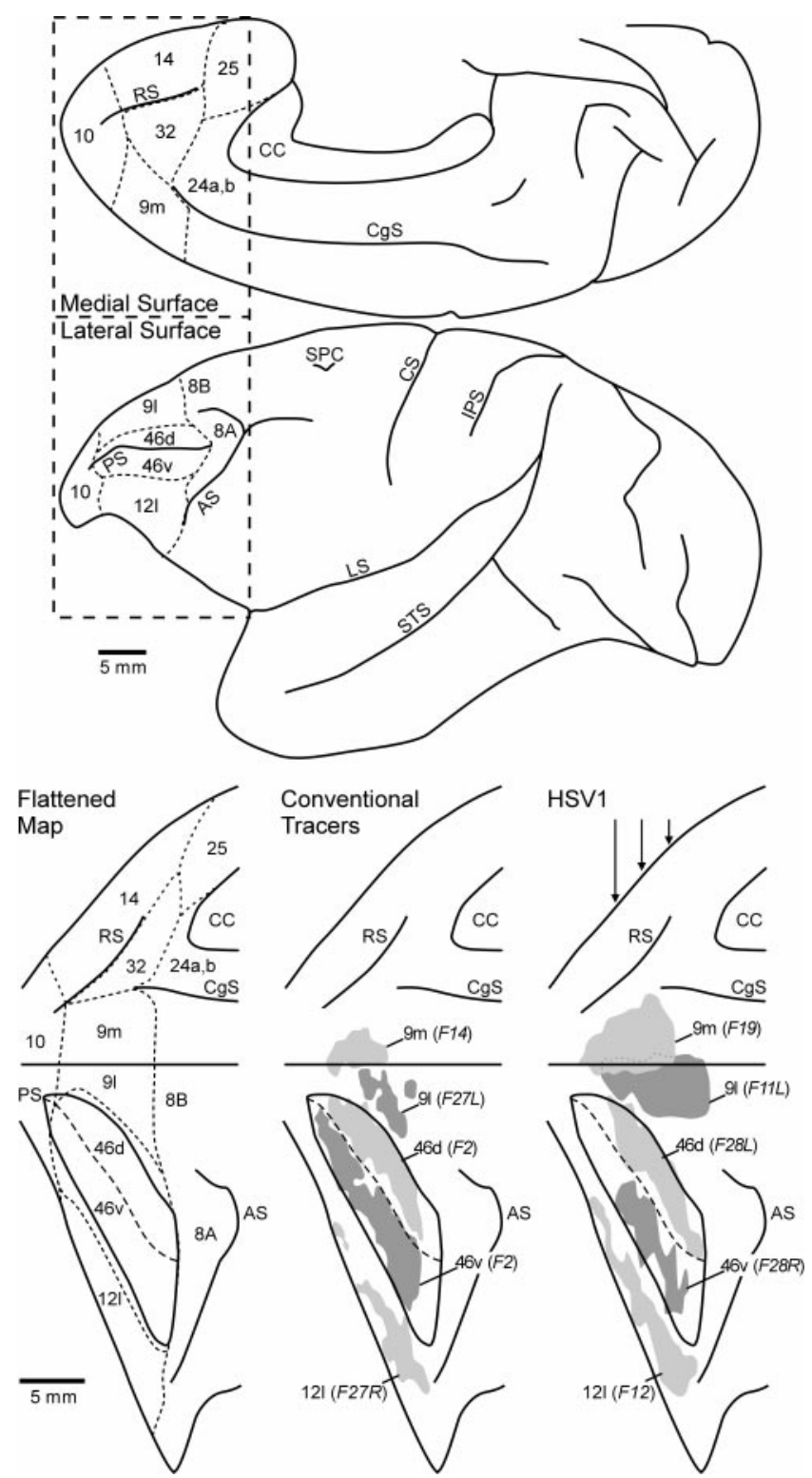

Figure 1. Location of HSV1 and conventional tracer injections. Top, The lateral surface and medial wall of the cerebral cortex of a cebus monkey. Bottom, The lateral surface and medial wall of the frontal lobe (boxed-in area above) aligned on the midline between the two and both banks of the principal sulcus unfolded. Left, A flattened map of the cytoarchitectonic regions of the prefrontal cortex according to the criteria of Walker (1940) and Barbas and Pandya (1989). Dashed lines indicate the approximate location of the borders between these regions. Middle, The reconstructed injection sites for different conventional tracer experiments. Right, Selected HSV1 injection sites. Shading is used to indicate the combined zones I and II of each injection site, and any regions of overlap are indicated with dotted lines. The approximate locations of the coronal sections through the HSV1 injection sites (see Fig. 2) are indicated with vertical arrows in the right panel. $A S$, Arcuate sulcus; $C C$, corpus callosum; $C S$, central sulcus; $C g S$, cingulate sulcus; IPS, intraparietal sulcus; $L S$, lateral sulcus; $P S$, principal sulcus; $R S$, rostral sulcus; $S P C$, superior precentral sulcus; $S T S$, superior temporal sulcus.

\section{Tracers}

To determine the origin of thalamic input, we injected one or two fluorescent tracers [fast blue (FB), diamidino yellow (DY), rhodamine dextran (RD), or nuclear yellow (NY)] into different sites within areas 9, 46, and 12 (Table 1). Multiple small injections of tracer were made in each cortical area (10-35 injections; $0.1-0.25 \mu \mathrm{l} / \mathrm{site}$ to a total volume of
1.7-3.5 $\mu \mathrm{l}$ /area; see also Table 1). To determine the origin of cerebellar input, we used the McIntyre-B strain of HSV1. This strain travels transneuronally in the retrograde direction in the CNS of primates (Zemanick et al., 1991; Strick and Card, 1992; Hoover and Strick, 1993, 1999; Strick et al., 1993; Lynch et al., 1994; Middleton and Strick, 1994). Three different preparations of this virus were used. In four hemispheres, we injected McIntyre-B obtained from Dr. David I. Bernstein [Gamble Institute of Medical Research, Cincinnati, $\mathrm{OH}$; for method of preparation, see McLean et al. (1989)]. In nine hemispheres, we injected a preparation of McIntyre-B that had been passaged in African green monkey kidney (Vero) cells [by Dr. Richard D. Dix, Jones Eye Institute, Little Rock, AR, or by Dr. Jennifer H. LaVail, University of California San Francisco, San Francisco, CA; for method of preparation, see LaVail et al. (1997)]. No substantial differences were observed in the overall patterns of labeling produced by these different preparations. Multiple small injections of virus were made into areas 9, 46, and 12 (17-59 injections; $0.05-0.25 \mu \mathrm{l} /$ site to a total volume of $2.1-5.0 \mu \mathrm{l} /$ area; see also Table 1).

\section{Survival period}

After the surgery, animals injected with HSV1 were placed in a BSL-2 isolation room for further observation and recovery. Animals that received injections of only fluorescent tracers were returned to the colony room. Observations of each animal's appearance and behavior were recorded every $4-8 \mathrm{hr}$, or more often as needed. All animals received dexamethasone $(0.1-0.5 \mathrm{mg} / \mathrm{kg}$, i.m. or p.o.) during the initial recovery period. Animals that showed signs of discomfort were given butorphenol (0.01-0.4 mg/ kg, i.m.) or buprenorphine (Buprenex, $0.01 \mathrm{mg} / \mathrm{kg}$, i.m.). If an animal developed partial or generalized seizures, it was given Phenobarbital $(2-6 \mathrm{mg} / \mathrm{kg}$, i.m., until the seizures were controlled; up to 40 $\mathrm{mg} / \mathrm{kg}$ in a $24 \mathrm{hr}$ period).

After the appropriate survival period (see Table 1), each animal was deeply anesthetized (ketamine hydrochloride, $25 \mathrm{mg} / \mathrm{kg}$, i.m.; pentobarbital sodium, 36-40 mg/kg, i.p.) and transcardially perfused using a three-step procedure (Rosene and Mesulam, 1978). The perfusates included $0.1 \mathrm{M}$ PBS, $4 \%(\mathrm{w} / \mathrm{v})$ paraformaldehyde in PBS, and $4 \%$ paraformaldehyde in PBS with $10 \%(\mathrm{v} / \mathrm{v})$ glycerine. After the perfusion, the brain and cerebellum were photographed, stereotaxically blocked, removed from the cranium, and stored in buffered $4 \%$ paraformaldehyde with $20 \%$ glycerine $\left(4^{\circ} \mathrm{C}\right)$ for $4-7 \mathrm{~d}$.

\section{Histology}

Blocks of neural tissue were frozen (Rosene et al., 1986) and serially sectioned in the coronal plane at a thickness of $50 \mu \mathrm{m}$. Every 10th section was counterstained with cresyl violet for cytoarchitectonic analysis [E. C. Gower; in Mesulam (1982)]. To identify neurons labeled by virus transport, we processed free-floating tissue sections according to the avidinbiotin-peroxidase method (ABC; Vectastain; Vector Laboratories, Burlingame, CA) using a commercially available antibody to HSV1 (Dako, Carpinteria, CA; 1:2000 dilution). At least every other section from these animals was reacted. Sections were mounted onto gelatin-coated glass slides, air dried, and then coverslipped with either Artmount or DPX. In animals injected with fluorescent tracers, at least every other section was immediately mounted onto slides. These slides were then kept refrigerated $\left(4^{\circ} \mathrm{C}\right)$ in darkness until examined.

\section{Analytic procedures}

We examined at least every fourth section through the injection site, thalamus, and cerebellum of experimental animals. Material from fluorescent tracer experiments was examined using fluorescent illumination [Leitz filters D (355-425 nm excitation wavelength) or N2 $(530-560 \mathrm{~nm}$ excitation wavelength)]. Sections reacted for HSV1 were examined using bright-field, dark-field, and polarized illumination.

Data from all experiments were plotted using a personal computer (PC)-based charting system (MD2; Minnesota Datametrics, Inc., St. Paul, MN). This system uses optical encoders to sense $x-y$ movements of the microscope stage and stores the coordinates of charted structures (e.g., section outlines, injection site zones, and labeled neurons). Digital images of selected structures were "captured" from the microscope using a video camera coupled to a high-resolution video-processing board in a PC. Software written in the laboratory enabled us to generate highresolution composites from multiple images.

\section{Determination of injection sites}

Conventional tracers. Three zones of labeling were evident at each fluorescent tracer injection site. Using established criteria (Bentivoglio et al., 


\section{HSV1 Animals}
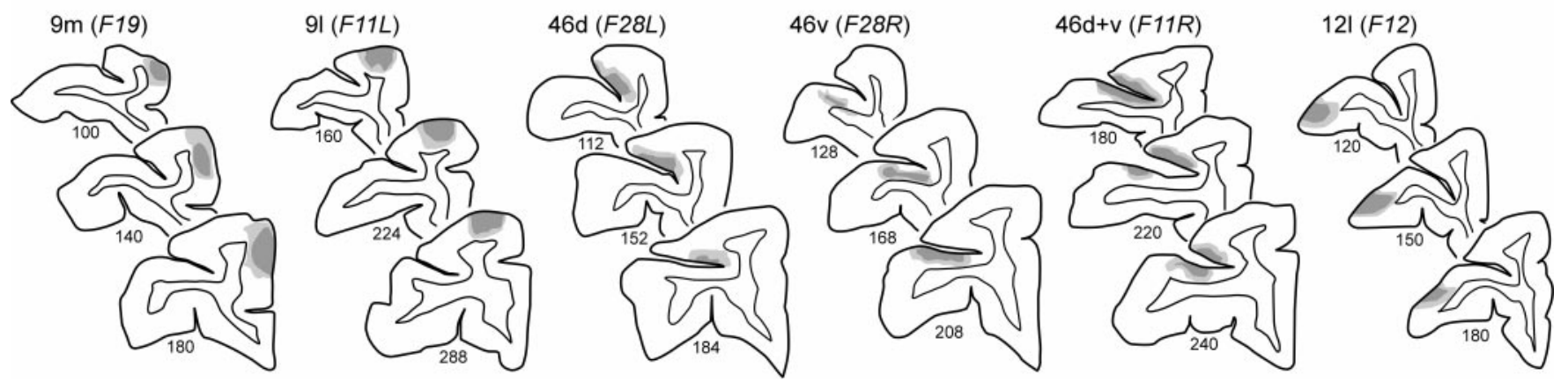

Figure 2. Cross sections through HSV1 injection sites (see Fig. 1). Low numbers indicate more rostral sections. Dark and light shading are used to indicate the central and peripheral zones, respectively, of the injection site in each section (see Results).

1980; Huisman et al., 1983; Kuypers and Huisman, 1984; Condé, 1987), we defined zone I as the central region surrounding the needle track that contained an almost solid mass of fluorescent material. Zone II contained large numbers of intensely fluorescent neurons and glia amid a bright background of fluorescence. Zone II gradually changed into zone III that contained some background tissue fluorescence and weakly fluorescent neurons and glia. The effective area of uptake and transport of these tracers is considered to be confined to zones I and II (Bentivoglio et al., 1980; Huisman et al., 1983; Kuypers and Huisman, 1984; Condé, 1987). Therefore, the maps of the injection sites (Figs. 1,2) only illustrate these two zones.

HSV1. Three concentric zones of labeling surrounded each virus injection site. Zone I contained the needle track and the highest density of viral staining and pathology. In some instances, the tissue in this zone disintegrated during tissue processing. Zone II contained a dense accumulation of infected neurons and glia, as well as a high degree of background staining. Zone III contained large numbers of labeled neurons but little or no background staining. There is evidence that the actual zone of uptake for transneuronal transport of HSV1 is limited to zone I (for discussion of this issue, see Strick and Card, 1992; Hoover and Strick, 1999). Because this issue is not resolved, we included both zones I and II in our reconstructions of injection sites (Figs. 1, 2).

\section{Reconstruction of injection sites}

The plots of individual sections were aligned on the junction of the medial wall of the hemisphere with the lateral surface (i.e., the midline of the hemisphere). Then, the medial wall and the lateral surface of the hemisphere, including the dorsal and ventral banks of the principal sulcus, were unfolded. This process created a flattened map of prefrontal cortex. The locations of injection sites and cytoarchitectonic borders were added to this map (e.g., Fig. 1). Cytoarchitectonic borders were drawn using the criteria of Walker (1940) and Barbas and Pandya (1989).

\section{Distribution and density of cerebellar labeling}

Cavalieri's estimator of morphometric volume (see Rosen and Harry, 1990) was used to determine the proportion of the dentate containing output neurons directed to each of the different prefrontal areas. This rule provides a statistically unbiased rectangular estimation of the volume of brain structures from area measurements of regularly spaced serial sections:

$$
V_{c}=d\left(\sum_{i=1}^{n}\left(y_{i}\right)\right)-(t) y_{\max },
$$

where $d$ is the distance between the sections that are being analyzed, $y_{i}$ is the cross-sectional area of the $i$ th section through the region of interest, $n$ is the total number of sections, $y_{\max }$ is the maximum value of $y$, and $t$ is the section thickness. A computer program was written in the laboratory to obtain two measurements from MD2 files of sections through the dentate: (1) the total cross-sectional area of the nucleus and (2) the area of the nucleus containing most $(>90 \%)$ of the labeled neurons.

\section{RESULTS}

Our results are divided into two major sections. In the first section, we present the results of experiments that used conventional tracers to examine the origin of thalamic inputs to regions of the prefrontal cortex. We focus on the patterns of labeling in thalamic regions that are known to be the target of cerebellar or basal ganglia efferents [e.g., nucleus ventralis anterior and lateralis (VA/VL) and nucleus medialis dorsalis (MD)]. In the second section, we present the results of experiments that used HSV1 as a transneuronal tracer to define the origin of cerebellar projections to the prefrontal cortex. In a subsequent report, we will present the patterns of retrograde transneuronal labeling observed in the output nuclei of the basal ganglia.

\section{Experiments with conventional tracers}

\section{Injection sites}

We injected fluorescent tracers into portions of areas 9, 46, and 12 in four hemispheres (Table 1; Fig. 1, bottom middle). In general, tracers spread 400-500 $\mu \mathrm{m}$ from the needle track at injection sites. Injections of NY and RD appeared to spread somewhat less than did injections of FB and DY.

Area 9. Areas $9 \mathrm{~m}$ and 91 were separately injected in two hemispheres (F14 and F27L). In F14, the injection site primarily involved the dorsal half of area $9 \mathrm{~m}$. It began $4.5 \mathrm{~mm}$ caudal to the frontal pole, extended caudally for $5 \mathrm{~mm}$, and ended $8 \mathrm{~mm}$ rostral to the genu of the arcuate sulcus. A portion of the peripheral zone of this injection site extended into the most medial part of area 91. In F27L, the injection site was entirely within the borders of 91 but was split into two regions by the presence of a large blood vessel. Overall, the injection site began $6.5 \mathrm{~mm}$ caudal to the frontal pole, extended caudally for $5 \mathrm{~mm}$, and ended $6.5 \mathrm{~mm}$ rostral to the genu of the arcuate sulcus.

Area 46. Areas 46d and 46v were injected with different tracers in a single hemisphere (F2). The injection sites filled the majority of these areas without spreading beyond the borders of area 46. Both injection sites began $\sim 4-5 \mathrm{~mm}$ caudal to the frontal pole and extended up to $2 \mathrm{~mm}$ rostral to the caudal tip of the principal sulcus.

Area 12. The area 121 was injected in a single hemisphere (F27R). The injection site was entirely within the borders of area 121. It began $6 \mathrm{~mm}$ caudal to the frontal pole, extended caudally for $8 \mathrm{~mm}$, and ended $5 \mathrm{~mm}$ rostral to the genu of the arcuate sulcus. 


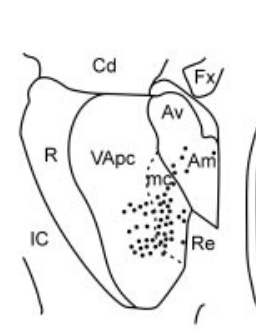

(439)

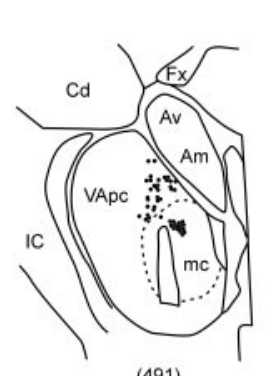

(491)
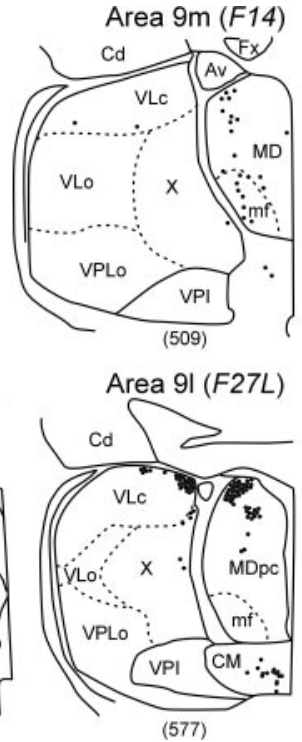

Area 46d( $(\circ)$, Area 46v $(\bullet)(F 2)$
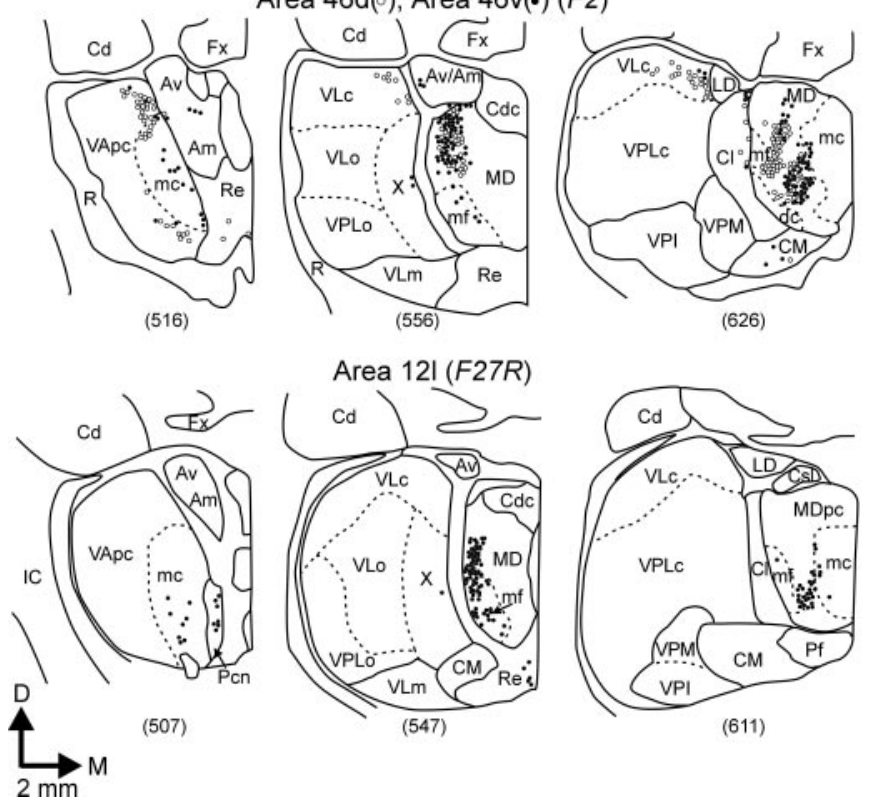

Figure 3. Thalamic input to the dorsal and lateral prefrontal cortex. Coronal cross sections through representative levels of the thalamus are shown for each conventional tracer experiment. Neurons labeled by retrograde transport from each area are indicated by dots, and nuclear borders are shown by solid or dotted lines. Thalamic nomenclature and abbreviations are according to Olszewski (1952). D, Dorsal; $M$, medial; $C d$, caudate; $c$, pars caudalis; $d c$, pars densocellularis; $F x$, fornix; $I C$, internal capsule; $L D$, nucleus lateralis dorsalis; $m c$, pars magnocellularis; $m f$, pars multiformis; $p c$, pars parvocellularis; $m$, pars medialis; $R$, nucleus reticularis; VPI, nucleus ventralis posterior inferior; VPL, nucleus ventralis posterior lateralis; $X$, area $\mathrm{X}$.

\section{Thalamic labeling in $V A / V L$ and $M D$}

Retrograde transport of conventional tracers from areas 9, 46, and 12 labeled many neurons in MD and in various subdivisions of the ventrolateral thalamus (Figs. 3, 4). Because we varied the amount and type of fluorescent tracer injected in different experiments, the absolute numbers of labeled neurons differed from case to case. Thus, to compare the results from different injections, we used the relative percentages of labeled neurons in specific regions of the thalamus (Fig. 4).

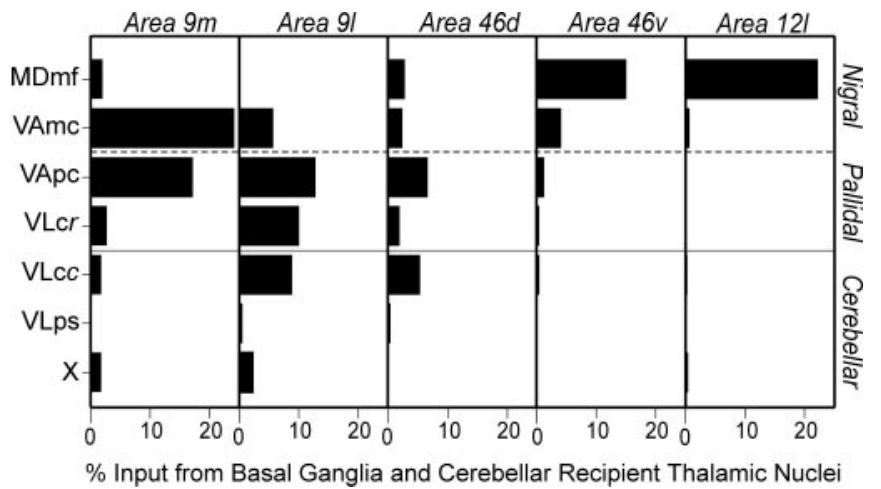

Figure 4. Inputs from basal ganglia- and cerebellar-recipient thalamic regions. The percent of total thalamic input to different regions of the prefrontal cortex is shown for those nuclei that are well known targets of basal ganglia and cerebellar projections. Only those basal ganglia- and cerebellar-recipient thalamic nuclei that contained labeling are shown. $V L c c$, Caudal VLc; VLcr, rostral VLc; ps, pars postrema.

Injections into the different cortical areas labeled neurons in topographically distinct regions of VA, VL, and MD. For example, neurons labeled by area 9 injections tended to be located in more dorsal and medial regions of MD than were neurons labeled by area 46 or area 12 injections (Fig. 3). The thalamic input to different subdivisions of areas 9 and 46 also was distinct. Within both MD and subdivisions of the ventrolateral thalamus, the neurons labeled by area 91 injections tended to be located dorsal to those labeled by area $9 \mathrm{~m}$ injections (see Fig. 3, first, second rows). Similarly, the neurons labeled by area $46 \mathrm{~d}$ injections tended to be located dorsal to those labeled by area 46v injections (Fig. 4, third row $)$. Only a small number of double-labeled neurons $(<5 \%$ of the total sample) were found in the thalamus of the animal that received multiple tracer injections into areas $46 \mathrm{~d}$ and $46 \mathrm{v}$ of the same hemisphere (F2, data not shown). These double-labeled neurons were most common in regions of the thalamus where neurons projecting to the two regions of area 46 were intermingled (Fig. 3). Overall, our findings on the distribution of labeled neurons in the thalamus were comparable with what others have reported after similar injections of conventional tracers into areas 9, 46, and 12 (Goldman-Rakic and Porrino, 1985; Barbas et al., 1991; Dermon and Barbas, 1994). The minor disparities between our results and those of previous studies are likely to be caused by small differences in the location of injection sites and the amounts of tracer injected.

Previous studies have shown that in primates the ventroanterior, ventrolateral, and mediodorsal thalamus can be grouped into subdivisions that receive primarily cerebellar, pallidal, or nigral input (see Percheron, 1977; Percheron et al., 1996; Sakai et al., 1996). We analyzed the relative inputs from these subdivisions of the thalamus to different prefrontal cortical areas to determine whether the anatomical substrate exists for the cerebellum and basal ganglia to influence the prefrontal cortex. Several portions of MD were excluded from this analysis because they are known to receive subcortical input from multiple sources other than the basal ganglia and cerebellum.

Area $9 \mathrm{~m}$. Approximately $50 \%$ of all the thalamic neurons labeled by injections into area $9 \mathrm{~m}$ were located in basal ganglia- or cerebellar-recipient thalamus (Fig. 4). The majority of these neurons were found in thalamic subdivisions that are the target of nigral (25\%, VAmc and MDmf) or pallidal (20\%, VApc and rostral VLc) efferents (see Figs. 3, first row, sections 439, 509; 4). 
In contrast, only a few labeled neurons were located in thalamic subdivisions that are the target of cerebellar efferents (5\%, caudal VLc, VLps, and X) (Figs. 3, first row, section 539; 4). Substantial numbers of labeled neurons also were found in a number of thalamic nuclei that are not the target of basal ganglia or cerebellar efferents [e.g., MDpc, 28\% (Fig. 3, first row, sections 509, 539 ), and $2-8 \%$ in each of the nucleus anterior ventralis and medialis $(\mathrm{Av} / \mathrm{Am})$, reuniens $(\mathrm{Re})$, paracentralis $(\mathrm{Pcn})$, centrum medianum and parafasicularis (CM/Pf), centralis densocellularis $(\mathrm{Cdc})$, centralis lateralis and centralis superior lateralis $(\mathrm{Cl} / \mathrm{Csl})$, and pulvinaris].

Area $9 l$. Nearly $45 \%$ of the thalamic neurons labeled by area 91 injections were found in basal ganglia- or cerebellar-recipient thalamus (Fig. 4). The largest proportion of labeled neurons $(30 \%)$ was found in thalamic subdivisions that are the target of pallidal efferents (23\%; Fig. 3, second row, section 491) and nigral efferents (7\%; Fig. 3, second row, section 491). Approximately half as many neurons $(15 \%)$ were found in cerebellar-recipient thalamus (caudal portions of VLc; Fig. 3, second row, sections 577, 611). Injections into area 91 labeled large numbers of neurons in MDpc (40\%; Fig. 3, second row, sections 577, 611) and small numbers of neurons $(5 \%)$ in several other thalamic nuclei [Av/ Am, Cdc, Cl/Csl, Re, Pcn, and lateralis posterior (LP)].

Area $46 d$. Approximately $24 \%$ of the thalamic neurons labeled by area $46 \mathrm{~d}$ injections were located in basal ganglia- or cerebellarrecipient nuclei (Fig. 4). The largest proportion was found in basal ganglia-recipient regions of the thalamus (16\%) with $10 \%$ located in subdivisions that receive input from pallidal efferents (VApc and VLcr; Fig. 3, third row, section 516) and 6\% located in subdivisions that receive input from nigral efferents (MDmf and VAmc; Fig. 3, third row, section 516). However, a comparable percentage $(8 \%)$ was found in subdivisions that are the target of cerebellar efferents (VLcc; Fig. 3, third row, section 626). The nigral-recipient thalamus contained the smallest proportion of labeled neurons (6\%; Fig. 3, third row, section 516). On the other hand, $\sim 70 \%$ of the thalamic neurons labeled in this case were in MDpc. Other thalamic nuclei (MDdc, MDmc, Cl/Csl, Pcn, CM/ $\mathrm{Pf}$, and pulvinar) contained smaller percentages of labeled neurons $(0.5-3 \%)$.

Area $46 v$. Slightly $<24 \%$ of the thalamic neurons labeled by area $46 \mathrm{v}$ injections were located in basal ganglia- or cerebellarrecipient nuclei (Fig. 4). The highest percentage (20\%) of labeled neurons was found in thalamic subdivisions that are the target of nigral efferents (MDmf and VAmc; Fig. 3, third row, sections 516, 556). Much smaller numbers of labeled neurons were found in thalamic nuclei that are the target of pallidal $(3 \%)$ or cerebellar $(1 \%)$ efferents. Over half of the total number of labeled neurons were found in MDpc (52\%), and small numbers of labeled neurons (3-4\%) also were found in other thalamic nuclei (Pcn, CM/Pf, and $\mathrm{MDmc})$.

Area $12 l$. Slightly $>23 \%$ of the thalamic neurons labeled by area 121 injections were located in basal ganglia- or cerebellarrecipient nuclei (Fig. 4). Nearly all of these neurons were in thalamic subdivisions that are the target of nigral efferents (MDmf and VAmc; see Fig. 3, fourth row, sections 507, 547). In contrast, $<1 \%$ of the labeled neurons were in thalamic subdivisions that are the target of cerebellar or pallidal efferents. MDpc contained just $>40 \%$ of the labeled neurons, and smaller percentages of labeled neurons $(1-6 \%)$ were found in other thalamic nuclei (MDdc, MDmc, CM/Pf, pulvinar, and LP).

Overall, there were several clear trends in the patterns of thalamic labeling observed after injections of fluorescent tracers into different portions of prefrontal cortex. As the injection site was moved from ventrolateral regions of prefrontal cortex (area 121) to more dorsomedial regions (area 9m), there was a marked increase in the number of labeled neurons in thalamic subdivisions that are the target of pallidal efferents. Labeling in nigraland cerebellar-recipient subdivisions of the thalamus followed different trends. The percentage of labeled neurons in the nigral thalamus was greatest after tracer injections into the most dorsomedial and ventrolateral areas examined (areas $9 \mathrm{~m}$ and 121), whereas labeling in cerebellar-recipient thalamus was greatest after tracer injections into dorsolateral areas of prefrontal cortex (areas 91 and 46d). These patterns of thalamic labeling lead to some clear predictions about the organization of basal ganglia and cerebellar "projections" to prefrontal cortex. They suggest that basal ganglia output has a widespread influence, whereas cerebellar output is more restricted. These predictions were tested using retrograde transneuronal transport of HSV1. The cerebellar results are presented in the next section.

\section{Experiments with HSV1}

\section{Injection sites}

We injected the McIntyre-B strain of HSV1 into selected portions of areas 9, 46, and 12 in 13 hemispheres (Table 1; Fig. 1, bottom right). In general, zones I and II of the injection sites extended 500-900 $\mu \mathrm{m}$ from the needle tracks, depending on the amount of virus injected (Fig. 2).

Area $9 \mathrm{~m}$. HSV1 was injected into slightly different rostrocaudal levels of area $9 \mathrm{~m}$ in two separate hemispheres. The first injection site filled up the majority of area 9m (F19, Figs. 1, 2). This injection site began $4 \mathrm{~mm}$ caudal to the frontal pole, extended caudally for 7 $\mathrm{mm}$, and ended $6 \mathrm{~mm}$ rostral to the genu of the arcuate sulcus. A small portion $(\sim 15 \%)$ of zone II from this injection site, but none of zone I, extended into adjacent portions of area 91. The second injection site in area $9 \mathrm{~m}$ began $9 \mathrm{~mm}$ caudal to the frontal pole, extended caudally for $6 \mathrm{~mm}$, and ended $2 \mathrm{~mm}$ rostral to the genu of the arcuate sulcus (F25, data not shown). As in the first area $9 \mathrm{~m}$ injection, a small portion of the peripheral zone of this injection site spread to involve the most medial portion of area 91. Although the majority of this injection site was clearly within area $9 \mathrm{~m}$, the caudal part of the peripheral zone of this injection site extended into a transitional cortical region between areas $9 \mathrm{~m}, 8 \mathrm{~B}$, and the presupplementary motor area. Because the patterns of transneuronal labeling in the output nuclei of the basal ganglia and cerebellum did not differ significantly between these two cases, we will describe and illustrate the results of transport from the case that was most confined to area 9m (F19).

Area 9l. The HSV1 injection sites in area 91 (F11L, Figs. 1, 2; F21, data not shown) differed somewhat in their rostrocaudal locations. In each case, a small portion $(<10 \%)$ of the peripheral zone of the injection site was found on the medial wall, in area $9 \mathrm{~m}$. The injection site in F11 began $5.5 \mathrm{~mm}$ caudal to the frontal pole, extended caudally for $8.5 \mathrm{~mm}$, and ended $4 \mathrm{~mm}$ rostral to the genu of the arcuate sulcus. The injection site in F21 (data not shown) began $5 \mathrm{~mm}$ caudal to the frontal pole, extended caudally for $6 \mathrm{~mm}$, and ended $5.5 \mathrm{~mm}$ rostral to the genu of the arcuate sulcus.

Areas $46 d$ and $46 v$. Virus injections into area 46 were made into both banks of the principal sulcus (areas 46d and 46v combined) in three hemispheres. The precise extent of tissue within the principal sulcus that contained virus varied among these cases. The most complete injection of area 46 was in F11R (Fig. 2). This 

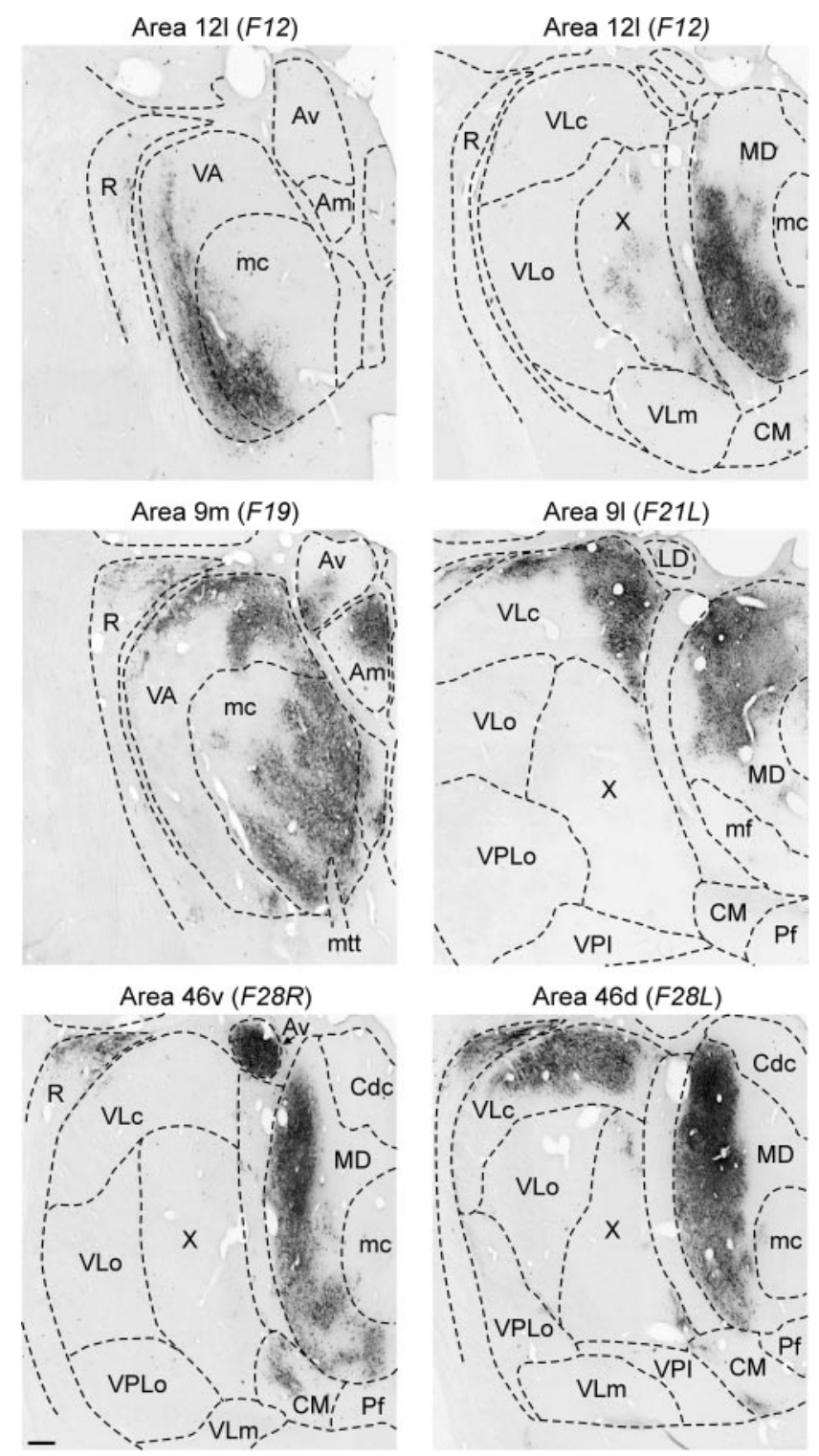

Figure 5. HSV1-labeled regions of the thalamus. The patterns of HSV1 labeling observed in the thalamus after injections into different regions of the prefrontal cortex are shown at a $5 \mathrm{~d}$ survival time. These sections were taken through the most dense regions of thalamic labeling in each case. Conventions are described in Figure 3. Scale bar, $400 \mu \mathrm{m}$. mtt, Mamillo thalamic tract.

injection site was entirely within area 46 and filled up much of the tissue within the middle and caudal portions of the principal sulcus, including a portion of the fundus of the sulcus (Fig. 2). It began $7 \mathrm{~mm}$ caudal to the frontal pole, extended caudally for 5 $\mathrm{mm}$, and ended $2 \mathrm{~mm}$ rostral to the caudal limit of the principal sulcus. The other virus injection sites in area 46 (F1 and F6, data not shown) were similar in their rostrocaudal location but involved smaller portions of the principal sulcus.

Selective injections into area $46 \mathrm{~d}$ or $46 \mathrm{v}$ were made in four hemispheres (F28L, F28R, F24L, and F24R; Table 1). The injection site in area 46d in F28L (Figs. 1, 2) was entirely within area $46 \mathrm{~d}$ and filled the middle and caudal portions of the dorsal bank of the principal sulcus. This injection site began $5 \mathrm{~mm}$ caudal to the frontal pole, extended caudally for $7 \mathrm{~mm}$, and ended $0.5 \mathrm{~mm}$ rostral to the caudal limit of the principal sulcus. The second injection site in area 46d (F24, data not shown) was also completely within area $46 \mathrm{~d}$. It began $5 \mathrm{~mm}$ caudal to the frontal pole, extended caudally for $5.5 \mathrm{~mm}$, and ended $2 \mathrm{~mm}$ rostral to the caudal limit of the PS. The two injection sites in area $46 \mathrm{v}$ were very similar; they both filled a considerable amount of the middle and caudal portions of area $46 \mathrm{v}$. These injection sites began $\sim 5$ $\mathrm{mm}$ caudal to the frontal pole, extended caudally for $7 \mathrm{~mm}$, and ended $2 \mathrm{~mm}$ rostral to the caudal limit of the principal sulcus (F28R, Fig. 1; F24R, data not shown). The only significant difference between these injection sites was that a portion of the injection site in F28R extended into the white matter just beneath the PS (F28R, Fig. 2).

Area 12l. The two HSV1 injection sites in area 121 (F12, Figs. 1, 2; F27L, data not shown) were nearly identical in their dimensions and locations. Both injection sites began $5 \mathrm{~mm}$ caudal to the frontal pole, extended caudally for $\sim 7.5 \mathrm{~mm}$, and ended $5 \mathrm{~mm}$ rostral to the genu of the arcuate sulcus. A small portion $(<5 \%)$ of the peripheral zone of the injection site in F12 extended into the orbital portion of area 12 (Fig. 2).

\section{Thalamic labeling}

A survival time of $5 \mathrm{~d}$ is long enough for HSV1 to be transported transneuronally via two orders of synaptic connections. Thus, at this survival time the thalamus will contain first-order neurons labeled via retrograde transport of HSV1 directly from the injection site. In addition, the thalamus will contain second-order neurons labeled via retrograde transport from the injection site to another brain area and then a second stage of retrograde transneuronal transport to thalamic neurons. In many cases, first- and second-order neurons can be distinguished by the intensity of staining and degree of cellular lysis (Hoover and Strick, 1999). In general, the distribution of first-order neurons in the thalamus after HSV1 injections into prefrontal cortex was consistent with that reported above for conventional tracers (compare Figs. 3, 5).

\section{Labeling in cerebellar output nuclei}

Most of the cerebellar neurons labeled via retrograde transneuronal transport of HSV1 from prefrontal cortex were found in the dentate nucleus (Table 2). Labeled neurons had darkly stained cell bodies, with somewhat lighter-stained dendrites radiating from the cell soma (Fig. 6). These second-order neurons had morphological features typical of cerebellar neurons that project to the thalamus (Tolbert et al., 1978; Nakano et al., 1980; Stanton and Orr, 1985).

Area 9m. The two animals that received injections of HSV1 into area $9 \mathrm{~m}$ displayed an average of just $>90$ labeled neurons in the output nuclei of the cerebellum (Table 2). Most of these neurons $(>90 \%)$ were found in the dentate nucleus, and only a small number $(0-6 \%)$ were located in the interpositus and fastigial nuclei. In fact, no labeled neurons were found in the anterior interpositus in case F25. Over $85 \%$ of the labeled neurons in the dentate were located contralateral to the injection site. In contrast, labeled neurons in the interpositus and fastigial nuclei were more bilaterally distributed. In both area $9 \mathrm{~m}$ cases, we found labeled neurons in a highly localized ventromedial region of the dentate, restricted to the middle and caudal third of the nucleus (Figs. 7,8 ). This labeled region represented $\sim 1 \%$ of the volume of the dentate.

Area 9l. Injections of HSV1 into area 91 labeled an average of $>400$ neurons in the cerebellar output nuclei (Table 2). The vast majority $(>96 \%)$ of these labeled neurons were found in the dentate and were located contralateral to the injection site. A 


\begin{tabular}{|c|c|c|c|c|c|}
\hline $\begin{array}{l}\text { Area } \\
\text { injected }\end{array}$ & Case & $\begin{array}{l}\text { Dentate } \\
\text { nucleus }\end{array}$ & $\begin{array}{l}\text { Anterior } \\
\text { interpositus }\end{array}$ & $\begin{array}{l}\text { Posterior } \\
\text { interpositus }\end{array}$ & $\begin{array}{l}\text { Fastigial } \\
\text { nucleus }\end{array}$ \\
\hline \multirow[t]{3}{*}{$9 \mathrm{~m}$} & F19 & $76 \quad(90.5)$ & $2 \quad(2.4)$ & $3 \quad(3.6)$ & $3 \quad(3.6)$ \\
\hline & $\mathrm{F} 25$ & $91 \quad(90.1)$ & 0 & $6 \quad(5.9)$ & $4 \quad(4.0)$ \\
\hline & Mean & $83.5(90.3)$ & $1 \quad(1.1)$ & $4.5(4.9)$ & $3.5(3.8)$ \\
\hline \multirow[t]{3}{*}{91} & F11L & $562 \quad(96.1)$ & 0 & $6 \quad(1.0)$ & $17 \quad(2.9)$ \\
\hline & F21L & $276 \quad(97.5)$ & 0 & $5 \quad(1.8)$ & $2 \quad(0.7)$ \\
\hline & Mean & $419 \quad(96.5)$ & 0 & $5.5(1.3)$ & $9.5(2.2)$ \\
\hline \multirow[t]{4}{*}{46} & $\mathrm{~F} 1$ & $98 \quad(95.1)$ & 0 & $5 \quad(4.9)$ & 0 \\
\hline & F6 & $70 \quad(97.2)$ & 0 & 0 & $2 \quad(2.8)$ \\
\hline & F11R & $486 \quad(94.4)$ & $2 \quad(0.4)$ & $9 \quad(1.7)$ & $18 \quad(3.5)$ \\
\hline & Mean & $218 \quad(94.8)$ & $0.7(0.3)$ & $4.7(2.0)$ & $6.7(2.9)$ \\
\hline \multirow[t]{3}{*}{$46 \mathrm{~d}$} & $\mathrm{~F} 24 \mathrm{~L}$ & $21 \quad(95.5)$ & 0 & 0 & $1 \quad(4.5)$ \\
\hline & F28L & $18 \quad(100.0)$ & 0 & 0 & 0 \\
\hline & Mean & $19.5(97.5)$ & 0 & 0 & $0.5(2.5)$ \\
\hline \multirow[t]{3}{*}{$46 v$} & F24R & $1 \quad(100.0)$ & 0 & 0 & 0 \\
\hline & F28R & 0 & 0 & 0 & 0 \\
\hline & Mean & 0.5 & 0 & 0 & 0 \\
\hline \multirow[t]{3}{*}{121} & $\mathrm{~F} 12$ & $2 \quad(66.7)$ & 0 & $1 \quad(33.3)$ & 0 \\
\hline & F27L & $4 \quad(57.1)$ & 0 & 0 & $3 \quad(42.9)$ \\
\hline & Mean & $3.0(60.0)$ & 0 & $0.5(10.0)$ & $1.5(30.0)$ \\
\hline
\end{tabular}

small number of labeled neurons were found in the posterior interpositus $(1 \%)$ and fastigial nuclei $(2 \%)$. The labeled neurons in the dentate were located in ventromedial regions of the caudal half of the nucleus. Neurons labeled by area 91 injections tended to be located more laterally than were the neurons labeled by area $9 \mathrm{~m}$ injections (Figs. 7, 8). The dentate region that contained labeled neurons after area 91 injections included $\sim 8 \%$ of the volume of the nucleus.

Area 46. Injections of HSV1 into area 46 labeled an average of $>200$ neurons in the cerebellar output nuclei (Table 2). Selective injections into different portions of area 46 showed that nearly all of this labeling was caused by transport from area 46d (Table 2). This result is consistent with our observation that area $46 \mathrm{~d}$ is a major target of thalamic regions that receive input from the cerebellum, whereas area $46 \mathrm{v}$ is not (see above; Fig. 4). The vast majority $(>95 \%)$ of neurons labeled after HSV1 injections into area 46 were found in the dentate and were located contralateral to the injection site (97\%). Labeled neurons in the dentate were most concentrated ventrally in the middle third of the nucleus rostrocaudally. In general, neurons that project to area 46 were located somewhat more laterally in the dentate than were those that project to area 91 (Figs. 7, 8). The dentate region that contained labeled neurons that project to area 46 represented $\sim 6.5 \%$ of the volume of the nucleus.

Area $12 l$. In contrast to the area 9 and area 46 results, injections of HSV1 into area 121 labeled very few neurons in the deep cerebellar nuclei. Most of the neurons that were labeled were found in ventral regions of the dentate contralateral to the injection site. The lack of labeled neurons in the dentate is consistent with the relative absence of input to area 12 from regions of the thalamus that are the target of cerebellar efferents (see above; Fig. 4).

Overall, the patterns of labeling that we observed in the dentate after transneuronal transport of HSV1 from prefrontal cortex are consistent with the predictions derived from experiments with conventional tracers. Both approaches indicate that cerebellar output targets specific portions of areas 9 and 46. In addition, virus transport uniquely demonstrates that this output originates from topographically distinct portions of the ventral dentate.

\section{DISCUSSION}

In this study, we examined the extent and topographic organization of cerebellar input to multiple regions of prefrontal cortex. The results from our studies with conventional tracers and with transneuronal transport of HSV1 indicate that cerebellar output does gain access to multiple areas of prefrontal cortex. These findings clearly differ from the classical view that cerebellar output is focused entirely on the primary motor cortex.

The use of retrograde transneuronal transport of HSV1 enabled us to determine the precise origin of cerebellothalamocortical projections to the prefrontal cortex. Clear shifts in the location of dense labeling in the dentate nucleus occurred with injections into different areas of prefrontal cortex. Such shifts were observed even after virus injections into adjacent subdivisions of the same cytoarchitectonic area (e.g., areas $9 \mathrm{~m}$ and 91; Figs. 7, 8). Thus, not only is the prefrontal cortex the target of cerebellar output, but this output appears to be topographically organized.

\section{Comparison with cerebellar inputs to other cortical areas}

In previous studies, we have used virus tracing to examine the cerebellar output to a number of motor areas of cortex. We found that injections of HSV1 into M1, ventral premotor area (PMv), dorsal premotor area (PMd), and frontal eyefield (FEF) all label neurons in the dentate nucleus (Zemanick et al., 1991; Hoover and Strick, 1993, 1999; Strick et al., 1993; Lynch et al., 1994; Dum and Strick, 1999). The neurons labeled after virus injections into M1, PMd, and PMv were all located in more dorsal regions of the dentate than were those labeled after prefrontal injections. Similarly, the neurons labeled by virus injections into the FEF were located in more caudal and lateral regions of the dentate than 


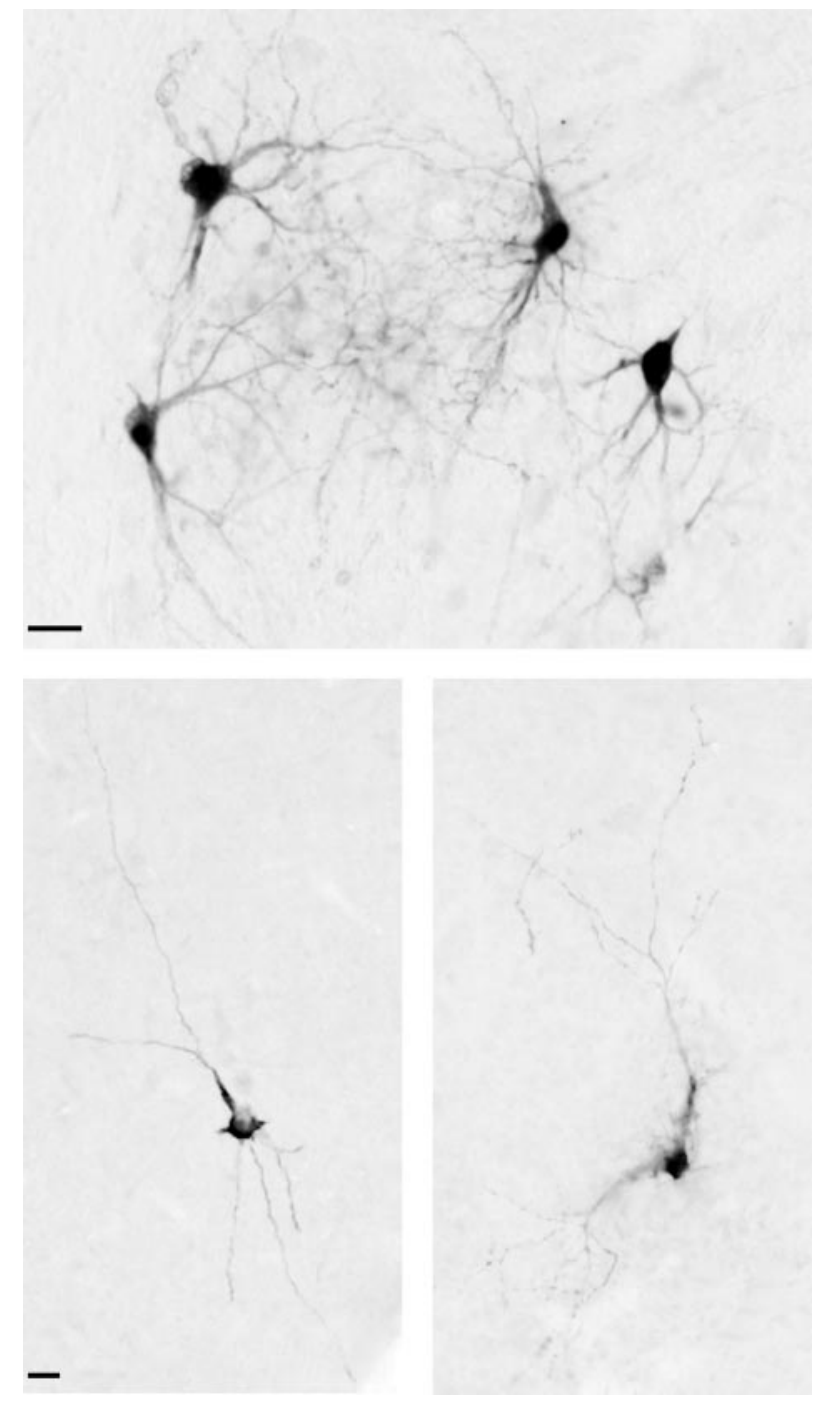

Figure 6. HSV1-labeled neurons in the cerebellar output nuclei. Top, HSV1-labeled neurons in the dentate nucleus are shown after injections into area 46 (F1). Bottom left, An example of an HSV1-labeled neuron in the fastigial nucleus is shown after injections of area $9 \mathrm{~m}$. Bottom right, An example of an HSV1-labeled neuron in the posterior interpositus nucleus after injection of area 9l. Scale bars, $25 \mu \mathrm{m}$.

were those labeled by prefrontal injections. These results indicate that cerebellar projections to prefrontal, oculomotor, and skeletomotor areas of cortex all appear to be derived from topographically distinct regions of the dentate. We have proposed that the cluster of neurons that projects to an individual cortical area creates a distinct "output channel" in the cerebellum (Strick et al., 1993; Middleton and Strick, 1997, 1998). The present results indicate that the dentate contains several output channels that are directed at different areas of prefrontal cortex.

Our results emphasize that areas 91 and 46d are major targets of dentate output. Interestingly, these are the regions of prefrontal cortex that project most densely on pontine nuclei that provide access to the input stage of cerebellar processing (Schmahmann and Pandya, 1995, 1997a). These observations suggest that a major structural feature of cerebellar interactions with prefrontal cortex is multiple, topographically closed loops. If this arrangement reflects a general principle of cerebrocerebellar architecture, then those areas of cerebral cortex that project to the input stage of cerebellar processing (i.e., the pontine nuclei) would also be the target of efferents from the output stage of cerebellar processing (i.e., the deep cerebellar nuclei). Widespread regions of the cerebral cortex, including cingulate, somatic sensory, posterior parietal, and visual areas, are known to project to the pontine nuclei (Brodal, 1978; Hartmann-von Monakow et al., 1981; Vilensky and van Hoesen, 1981; Leichnetz et al., 1984; Glickstein et al., 1985; Schmahmann and Pandya, 1995, 1997a). Our hypothesis predicts that most of these cortical areas would also be the target of cerebellar output. To date, the volume of the dentate occupied by the known output channels to skeletomotor, oculomotor, and prefrontal areas of cortex represents only $\sim 60 \%$ of the volume of the nucleus. Consequently, the cortical targets of a major portion of dentate output remain to be determined. Even so, it is clear that a considerable amount of the cerebrocerebellar interactions operate outside the domain of motor control.

\section{Functional implications}

Our results indicate that output channels in the ventral dentate project to specific portions of the prefrontal cortex. These observations raise an important question; namely, what is the functional contribution of this pathway? In this section, we will describe results based on a variety of experimental approaches that suggest that dentate output channels to prefrontal cortex are involved in aspects of higher executive function like planning, working memory, and sequential behavior.

\section{Single-neuron recording in trained primates}

Mushiake and Strick (1993, 1995) recorded from the dentate nucleus in monkeys trained to perform sequences of movements, three elements in length. In one component of the task, three visual cues were presented to the monkey. The monkey had to remember the position of the cues and the order in which they were presented. Then, after a variable instructed delay period, the monkey performed the remembered sequence as quickly as possible. Approximately $15 \%$ of the neurons recorded in the dentate during this task displayed changes in activity during the instructed delay period. The activity of some instruction-related neurons was specific for the particular sequence of movements the animal had to remember. These patterns of activity resemble those of neurons in area 46 recorded during a similar instructed delay task that involved arm movements (Funahashi et al., 1997). The dentate neurons that displayed instruction-related activity tended to be located in ventral regions of the nucleus that project to areas 9 and 46. These results suggest that dentate activity could be involved in the generation and/or maintenance of delay activity in prefrontal cortex.

\section{Imaging studies in human subjects}

Jueptner et al. (1997a,b) found significant activation in ventrolateral portions of the deep cerebellar nuclei, as well as in portions of areas 9 and 46, during the learning of new sequences of finger movements. They also observed peak activations laterally in the cerebellar hemispheres and at thalamic sites in caudal paralaminar MD. Thus, every potential site in the cerebellothalamocortical pathway from the neocerebellum to the prefrontal cortex displayed activation during a sequence-learning task in humans.

Kim et al. (1994) specifically examined dentate activation in human subjects by the use of high-field functional MRI. They found that the magnitude and extent of activation in the dentate during attempts to solve a Peg-Board puzzle were greater than that observed when subjects simply performed visually guided 

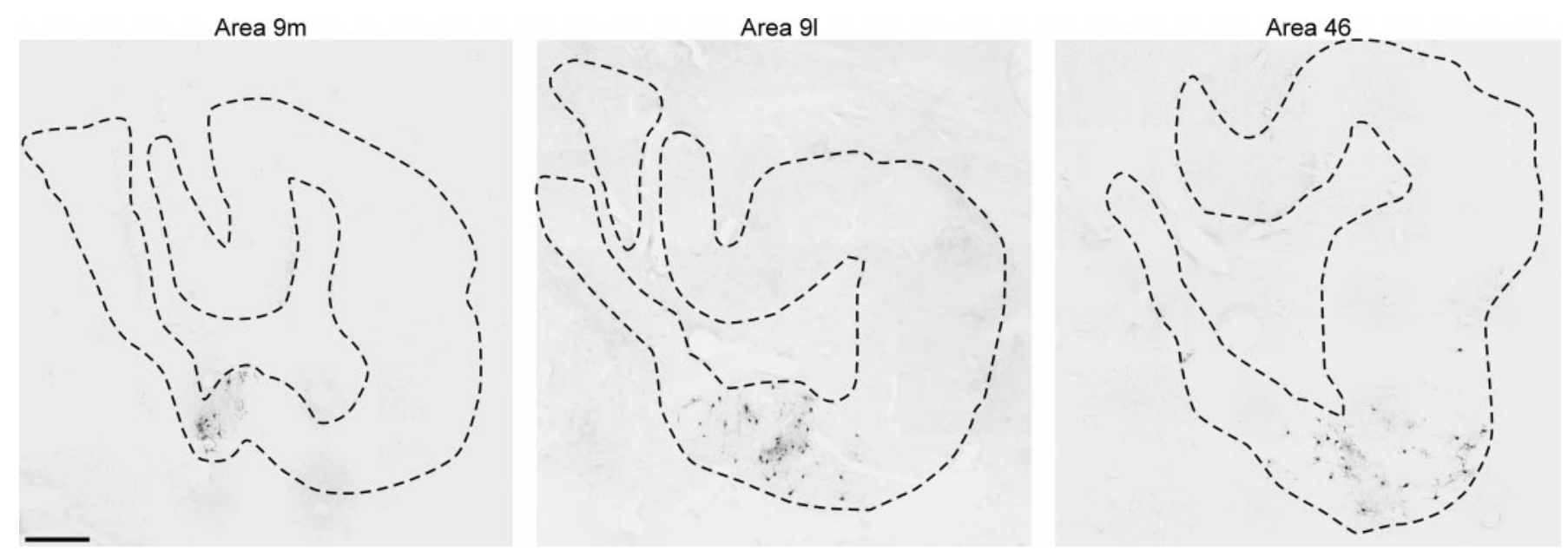

Figure 7. Comparison of dentate labeling after HSV1 injections of area 9. Sections at the same level of the dentate are shown after injections of HSV1 into area $9 \mathrm{~m}$ (left), area 91 (middle), or area 46 (right). The dashed lines indicate the borders of the dentate nucleus. Note the difference in the location of the labeled neurons within the dentate between cases. Scale bar, $500 \mu \mathrm{m}$.
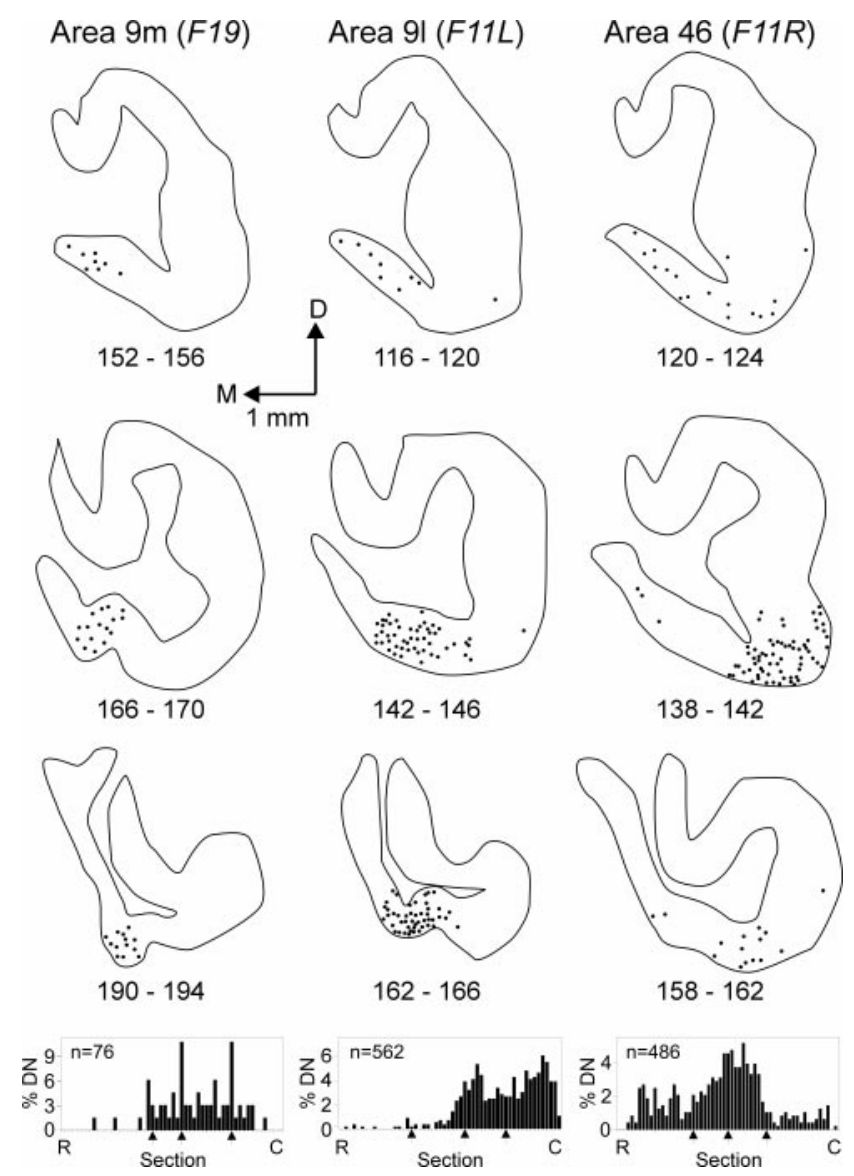

Figure 8. Origin of dentate projections to areas 9 and 46. Sections through the middle of the dentate nucleus are shown after injections into area $9 \mathrm{~m}$ (left), area 91 (middle), or area 46 (right). The rostrocaudal distribution of labeled neurons in the dentate for each case is shown at the bottom of the figure, with the locations of the sections shown above indicated by the arrows. $D N$, Dentate nucleus; $R$, rostral; $C$, caudal.

movements of pegs. Thus, dentate activation was not simply related to movement per se (see also Gao et al., 1996). Moreover, ventral regions of the dentate appeared to be especially activated during attempts to solve the Peg-Board puzzle. Overall, imaging studies in humans provide support for the suggestion that output channels in the ventral dentate that innervate prefrontal cortex are involved in the learning of new sequences, spatial working memory, planning, and rule-based learning.

\section{Cerebellar lesions}

In addition to the classical motor deficits, there is considerable evidence that cerebellar pathology in humans can lead to deficits in the performance of cognitive tasks that require rule-based learning, judgment of temporal intervals, visuospatial analysis, and shifting attention between sensory modalities, as well as working memory and planning (for review, see Leiner et al., 1986, 1987, 1989, 1991, 1993; Botez et al., 1989; Ivry and Keele, 1989; Schmahmann, 1991, 1997; Akshoomoff and Courchesne, 1992; Fiez et al., 1992; Grafman et al., 1992; Schmahmann and Sherman, 1998). Many of these deficits reflect functions normally thought to be subserved by areas of prefrontal cortex. Based on our results, one interpretation of the origin of these deficits is that they result from an interruption of input to the prefrontal cortex from the cerebellum. Similarly, one might predict that damage to the ventral portion of the dentate, or to the regions of cerebellar cortex that innervate it, would produce deficits that resemble those seen after lesions of areas 9 or 46. In fact, a study by Fiez et al. (1992) provides some support for this prediction. They described a patient, designated RC1, who had circumscribed damage to the lateral portion of his right cerebellar cortex. This patient exhibited few classical signs of cerebellar damage but was impaired on the performance of specific types of rule-based language and memory tasks. The deficits appeared on tasks that in normal subjects activate lateral portions of the cerebellar hemispheres and areas 9 and 46 (Petersen et al., 1988; Raichle et al., 1994; Fiez et al., 1996). Recent anatomical studies suggest that the portions of the cerebellum damaged in RC1 are part of the cerebellar loop with the prefrontal cortex (Kelly and Strick, 1998). Thus, the cognitive deficits in RC1 may have been a consequence of interrupting this circuit.

Results of studies on patients with cerebellar damage suggest that the cerebellum also is involved in sequence learning and performance (Pascual-Leone et al., 1993; Molinari et al., 1997), behaviors that have been shown to rely, at least in part, on certain 
prefrontal areas (Jacobsen, 1936; Petrides and Milner, 1982; Jenkins et al., 1994; Pascual-Leone et al., 1995, 1996; Petrides, 1995; Hikosaka et al., 1996; Funahashi et al., 1997; Jueptner et al., 1997a,b; Sakai et al., 1998). Thus, it is possible that the output channels that link the ventral dentate to areas of prefrontal cortex may have a function in the learning and execution of sequential behavior. Two recent experimental tests of this suggestion have given conflicting results. Hikosaka et al. (1998) examined the effects of focal inactivation of movement-related sites within the dentate on the learning and performance of a sequential buttonpress task. They concluded that the "... dentate nucleus is used for the storage or retrieval of long-term procedural memories." On the other hand, Nixon and Passingham (2000) examined the effects of bilateral excitotoxic lesions of the lateral cerebellar nuclei on a similar sequential task. They suggested that the cerebellum "... is not essential for learning or recall" but is "... crucially involved in the process by which motor sequences become automatic with extended practice." Perhaps the disparate conclusions result, in part, from differences in the size and extent of damage within the dentate. Our anatomical data indicate that even small shifts in the lesion site could effect different output channels within the dentate.

\section{Cerebellar involvement in psychiatric disorders}

Cerebellar abnormalities have been reported in numerous studies of neuropsychiatric disorders, including depression, Tourette's syndrome, attention deficit disorder, autism, William's syndrome, and schizophrenia, to name but a few (Heath et al., 1979; Weinberger et al., 1979; Snider, 1982; Hamilton et al., 1983; Bauman and Kemper, 1985; Joseph et al., 1985; Shelton and Weinberger, 1986; Yates et al., 1987; Courchesne et al., 1988; Volkow, 1992; Jurjus et al., 1994; Martin and Albers, 1995; Andreasen et al., 1996; Courchesne, 1997; Filipek et al., 1997; Harrison, 1999). Many of these studies have been inconclusive and often confounded by the effects of medication. Nonetheless, it is becoming apparent that some of the changes reported in these studies could reflect involvement of the same anatomical circuits we have described. For example, among the most consistent findings in studies of schizophrenia are decreased metabolism in areas 9 and 46, cytoarchitectonic alterations in thalamic-recipient layers of areas 9 and 46, and reductions in neuron number in the MD nucleus of the thalamus (for review, see Harrison, 1999). The possibility that these findings could all be related to dysf unctions of a cerebellar output channel to the prefrontal cortex was suggested by the work of Andreasen et al. (1996). These investigators reported alterations in metabolism in the cerebellum, thalamus, and dorsal prefrontal cortex of schizophrenic subjects during a memory recall task and speculated that schizophrenic subjects might suffer from a form of dysmetria that involved cognitive operations, as opposed to the dysmetria classically associated with cerebellar damage. Clearly, more detailed analyses of the cerebellar changes in schizophrenia and a more complete map of the relations between areas of cerebral and cerebellar cortex will enable a better assessment of the potential cerebellar involvement in schizophrenia and other psychiatric disorders.

\section{Anatomical and functional specificity of cerebellar projections to prefrontal cortex}

The present results provide further clues about the functional contributions of the cerebellar projections to the prefrontal cortex. We found that cerebellar output targets dorsal areas of the prefrontal cortex (9 and 46d) but primarily avoids ventral pre- frontal areas (12 and 46v). A complete discussion of the functional differences between dorsal and ventral areas of the prefrontal cortex is beyond the scope of this report. However, there is some agreement that dorsal areas of the prefrontal cortex are involved in spatial working memory and planning and are a major site of termination of the "dorsal stream" of visual processing, whereas ventral areas of the prefrontal cortex are involved in the working memory for objects or visual discrimination learning and are a major target of the ventral stream of visual processing (see Petrides and Milner, 1982; Goldman-Rakic, 1987; Passingham, 1993; Wilson et al., 1994; Petrides, 1995; Fuster, 1997; Rushworth et al., 1997). Thus, our results suggest that the cerebellar projection to the prefrontal cortex is particularly concerned with spatial working memory, planning, and other functions associated with the dorsal stream of visual processing.

In summary, the available anatomical, physiological, and behavioral data suggest that the cerebellum is involved not only in the control of movement but also in many aspects of cognitive behavior like planning, working memory, and sequential behavior. Our results provide the anatomical substrate for a cerebellar influence on processing within the prefrontal cortex. Further studies are necessary to determine the full extent of the cerebral cortex that is the target of cerebellar output. Clearly, we have only begun to appreciate the diverse range of behaviors that could be influenced by the cerebellum.

\section{REFERENCES}

Akshoomoff NA, Courchesne E (1992) A new role for the cerebellum in cognitive function. Behav Neurosci 106:731-738.

Allen GI, Tsukahara N (1974) Cerebrocerebellar communication systems. Physiol Rev 54:957-1006.

Allen GI, Gilbert PF, Yin TC (1978) Convergence of cerebral inputs onto dentate neurons in monkey. Exp Brain Res 32:151-170.

Andreasen NC, O'Leary DS, Cizaldo T, Arndt S, Rezai K, Boles Ponto LL, Watkins GL, Hichwa RD (1996) Schizophrenia and cognitive dysmetria: a positron-emission tomography study of dysfunctional prefrontal-thalamic-cerebellar circuitry. Proc Natl Acad Sci USA 93:9985-9990.

Asanuma C, Thach WT, Jones EG (1983) Distribution of cerebellar terminations in the ventral lateral thalamic region of the monkey. Brain Res Rev 5:237-265.

Barbas H, Pandya DN (1989) Architecture and intrinsic connections of the prefrontal cortex in the rhesus monkey. J Comp Neurol 286:353-375

Barbas H, Haswell Henion TH, Dermon CR (1991) Diverse thalamic projections to the prefrontal cortex in the rhesus monkey. J Comp Neurol 313:65-94.

Bauman M, Kemper TL (1985) Histoanatomic observations of the brain in early infantile autism. Neurology 35:866-874.

Bentivoglio M, Kuypers HGJM, Catsman-Berevoets CE, Loewe H, Dann O (1980) Two new fluorescent retrograde neuronal tracers which are transported over long distances. Neurosci Lett 18:25-30.

Botez MI, Botez T, Elie R, Attig E (1989) Role of the cerebellum in complex human behavior. Ital J Neurol Sci 10:291-300.

Brodal P (1978) The corticopontine projection in the rhesus monkey. Origin and principles of organization. Brain 101:251-283.

Brooks VB, Thach WT (1981) Cerebellar control of posture and movement. In: Handbook of physiology, Sec 1, The nervous system, Vol 2, Motor control, Pt II (Brooks VB, ed), pp 877-946. Bethesda, MD: American Physiological Society.

Condé F (1987) Further studies on the use of the fluorescent tracers fast blue and diamidino yellow: effective uptake area and cellular storage sites. J Neurosci Methods 21:31-43.

Courchesne E (1997) Brainstem, cerebellar and limbic neuroanatomical abnormalities in autism. Curr Opin Neurobiol 7:269-278.

Courchesne E, Yeung-Courchesne R, Press GA, Hesselink JR, Jernigan TL (1988) Hypoplasia of cerebellar vermal lobules VI and VII in autism. N Engl J Med 318:1349-1354.

Darian-Smith C, Darian-Smith I, Cheema SS (1990) Thalamic projections to sensorimotor cortex in the macaque monkey: use of multiple retrograde fluorescent tracers. J Comp Neurol 299:17-46.

Dermon CR, Barbas H (1994) Contralateral thalamic projections predominantly reach transitional cortices in the rhesus monkey. J Comp Neurol 344:508-531.

Dum RP, Strick PL (1999) Pallidal and cerebellar inputs to the digit 
representations of the lateral premotor areas. Soc Neurosci Abstr 25:1925.

Evarts EV, Thach WT (1969) Motor mechanisms of the CNS: cerebrocerebellar interrelations. Annu Rev Physiol 31:451-498.

Fiez JA, Petersen SE, Cheney MK, Raichle ME (1992) Impaired nonmotor learning and error detection associated with cerebellar damage. Brain 115:155-178.

Fiez JA, Raife EA, Balota DA, Schwarz JP, Raichle ME, Petersen SE (1996) A positron emission tomography study of the short-term maintenance of verbal information. J Neurosci 16:808-822.

Filipek PA, Semrud-Clikeman M, Steingard RJ, Renshaw PF, Kennedy DN, Biederman J (1997) Volumetric MRI analysis comparing subjects having attention-deficit hyperactivity disorder with normal controls. Neurology 48:589-601

Funahashi S, Inoue M, Kubota K (1997) Delay-period activity in the primate prefrontal cortex encoding multiple spatial positions and their order of presentation. Behav Brain Res 84:203-223.

Fuster J (1997) The prefrontal cortex. New York: Raven.

Gao JH, Parsons LM, Bower JM, Xiong J, Li J, Fox PT (1996) Cerebellum implicated in sensory acquisition and discrimination rather than motor control. Science 272:545-547.

Glickstein M, May JG, Mercier BE (1985) Corticopontine projection in the macaque: the distribution of labelled cortical cells after large injections of horseradish peroxidase in the pontine nuclei. J Comp Neurol 235:343-359.

Goldman-Rakic PS (1987) Circuitry of primate prefrontal cortex and regulation of behavior by representational memory. In: Handbook of physiology, Sec 1, The nervous system, Vol V (Plum F, ed), pp 373-413. Bethesda, MD: American Physiological Society.

Goldman-Rakic PS, Porrino LJ (1985) The primate mediodorsal (MD) nucleus and its projection to the frontal lobe. J Comp Neurol 242:535-560.

Gonzalo-Ruiz A, Leichnetz GR (1990) Connections of the caudal cerebellar interpositus complex in a new world monkey (Cebus apella). Brain Res Bull 25:919-927.

Grafman J, Litvan I, Massaquoi S, Stewart M, Sirigu A, Hallett M (1992) Cognitive planning deficit in patients with cerebellar atrophy. Neurology 42:1493-1496.

Hamilton NG, Frick RB, Takahashi T, Hopping MW (1983) Psychiatric symptoms and cerebellar pathology. Am J Psychiatry 140:1322-1326.

Harrison PJ (1999) The neuropathology of schizophrenia. A critical review of the data and their interpretation. Brain 122:593-624.

Hartmann-von Monakow K, Akert K, Kunzle H (1981) Projection of precentral, premotor and prefrontal cortex to the basilar pontine grey and to nucleus reticularis tegmenti pontis in the monkey (Macaca fascicularis). Schweiz Arch Neurol Neurochir Psychiatr 129:189-208.

Heath RG, Franklin DE, Shraberg D (1979) Gross pathology of the cerebellum in patients diagnosed and treated as functional psychiatric disorders. J Nerv Ment Dis 167:585-592.

Hikosaka O, Sakai K, Miyauchi S, Takino R, Sasaki Y, Putz B (1996) Activation of human presupplementary motor area in learning of sequential procedures: a functional MRI study. J Neurophysiol 76:617-621.

Hikosaka O, Miyashita K, Miyachi S, Sakai K, Lu X (1998) Differential roles of the frontal cortex, basal ganglia, and cerebellum in visuomotor sequence learning. Neurobiol Learn Mem 70:137-149.

Hoover JE, Strick PL (1993) Multiple output channels in the basal ganglia. Science 259:819-821.

Hoover JE, Strick PL (1999) The organization of cerebellar and basal ganglia outputs to primary motor cortex as revealed by retrograde transneuronal transport of herpes simplex virus type 1 . J Neurosci 19:1446-1463.

Huisman AM, Kuypers HGJM, Condé F, Keizer K (1983) Collaterals of rubrospinal neurons to the cerebellum in rat. A retrograde fluorescent double labeling study. Brain Res 264:181-196.

Ivry RB, Keele SW (1989) Timing functions of the cerebellum. J Cogn Neurosci 1:136-152.

Jacobsen CF (1936) Studies of cerebral function in primates. I. The functions of the frontal association areas in monkeys. Comp Psychol Monogr 13:3-60.

Jenkins IH, Brooks DJ, Nixon PD, Frackowiak RS, Passingham RE (1994) Motor sequence learning: a study with positron emission tomography. J Neurosci 14:3775-3790.

Joseph AB, Anderson WH, O'Leary DH (1985) Brainstem and vermis atrophy in catatonia. Am J Psychiatry 142:352-354.

Jueptner M, Stephan KM, Frith CD, Brooks DJ, Frackowiak RS, Passingham RE (1997a) Anatomy of motor learning. I. Frontal cortex and attention to action. J Neurophysiol 77:1313-1324.

Jueptner M, Frith CD, Brooks DJ, Frackowiak RS, Passingham RE (1997b) Anatomy of motor learning. II. Subcortical structures and learning by trial and error. J Neurophysiol 77:1325-1337.

Jurjus GJ, Weiss KM, Jaskiw GE (1994) Schizophrenia-like psychosis and cerebellar degeneration. Schizophr Res 12:183-184.

Kalil K (1981) Projections of the cerebellar and dorsal column nuclei upon the thalamus of the rhesus monkey. J Comp Neurol 195:25-50.
Kelly RM, Strick PL (1998) Cerebro-cerebellar "loops" are closed. Soc Neurosci Abstr 24:1407.

Kemp JM, Powell TPS (1971) The connexions of the striatum and globus pallidus: synthesis and speculation. Philos Trans R Soc Lond [Biol] 262:441-457.

Kievit J, Kuypers HGJM (1972) Fastigial cerebellar projections to the ventrolateral nucleus of the thalamus and the organization of the descending pathways. In: Corticothalamic projections and sensorimotor activities (Frigyes T, Rinvik E, Yahr MO, eds), pp 91-114. New York: Raven.

Kievit J, Kuypers HGJM (1977) Organization of thalamo-cortical connexions to the frontal lobe in the rhesus monkey. Exp Brain Res 29:299-322.

Kim S-G, Ugurbil K, Strick PL (1994) Activation of a cerebellar output nucleus during cognitive processing. Science 265:949-951.

Kusama T, Mabuchi M, Sumino T (1971) Cerebellar projections to the thalamic nucleus in the monkey. Proc Jap Acad 47:505-510.

Kuypers HGJM, Huisman AM (1984) Fluorescent neuronal tracers. Adv Cell Neurobiol 5:307-340.

LaVail JH, Topp KS, Giblin PA, Garner JA (1997) Factors that contribute to the transneuronal spread of herpes simplex virus. J Neurosci Res 49:485-496.

Leichnetz GR, Smith DJ, Spencer RF (1984) Cortical projections of the paramedian tegmental and basilar pons in the monkey. J Comp Neurol 228:388-408

Leiner HC, Leiner AL, Dow RS (1986) Does the cerebellum contribute to mental skills? Behav Neurosci 100:443-454.

Leiner HC, Leiner AL, Dow RS (1987) Cerebro-cerebellar learning loops in apes and humans. Ital J Neurol Sci 8:425-436.

Leiner HC, Leiner AL, Dow RS (1989) Reappraising the cerebellum: what does the hindbrain contribute to the forebrain? Behav Neurosci 103:998-1008.

Leiner HC, Leiner AL, Dow RS (1991) The human cerebro-cerebellar system: its computing, cognitive, and language skills. Behav Brain Res 44:113-128.

Leiner HC, Leiner AL, Dow RS (1993) Cognitive and language functions of the human cerebellum. Trends Neurosci 16:444-447.

Lynch JC, Hoover JE, Strick PL (1994) Input to the primate frontal eye field from the substantia nigra, superior colliculus, and dentate nucleus demonstrated by transneuronal transport. Exp Brain Res 100:181-186.

Martin P, Albers M (1995) Cerebellum and schizophrenia: a selective review. Schizophr Bull 21:241-250.

Matelli M, Luppino G (1996) Thalamic input to mesial and superior area 6 in the macaque monkey. J Comp Neurol 372:59-87.

Matelli M, Luppino G, Fogassi L, Rizzolatti G (1989) Thalamic input to inferior area 6 and area 4 in the macaque monkey. J Comp Neurol $280: 468-488$

McLean JH, Shipley MT, Bernstein DI (1989) Golgi-like, transneuronal retrograde labelling with CNS injections of herpes simplex virus type 1. Brain Res Bull 22:867-881.

Mesulam MM (1982) Tracing neural connections (Mesulam MM, ed), pp 1-151. New York: Wiley.

Middleton FA, Strick PL (1994) Anatomical evidence for cerebellar and basal ganglia involvement in higher cognitive function. Science 266:458-461.

Middleton FA, Strick PL (1996) The temporal lobe is a target of output from the basal ganglia. Proc Natl Acad Sci USA 93:8683-8687.

Middleton FA, Strick PL (1997) Dentate output channels: motor and cognitive components. Prog Brain Res 114:555-568.

Middleton FA, Strick PL (1998) Cerebellar output: motor and cognitive channels. Trends Cogn Sci 2:348-354

Middleton FA, Strick PL (2000) Basal ganglia and cerebellar loops: motor and cognitive circuits. Brain Res Brain Res Rev 31:236-250.

Miyata M, Sasaki K (1983) HRP studies on thalamocortical neurons related to the cerebellocerebral projection in the monkey. Brain Res 274:213-224.

Molinari M, Leggio MG, Solida A, Ciorra R, Misciagna S, Silveri MC, Petrosini L (1997) Cerebellum and procedural learning: evidence from focal cerebellar lesions. Brain 120:1753-1762.

Mushiake H, Strick PL (1993) Preferential activity of dentate neurons during limb movements. J Neurophysiol 70:2660-2664.

Mushiake H, Strick PL (1995) Cerebellar and pallidal activity during instructed delay periods. Soc Neurosci Abstr 21:411.

Nakano K, Takimoto T, Kayahara T, Takeuchi Y, Kobayashi Y (1980) Distribution of cerebellothalamic neurons projecting to the ventral nuclei of the thalamus: an HRP study in the cat. J Comp Neurol 194:427-439

Nixon PD, Passingham RE (2000) The cerebellum and cognition: cerebellar lesions do not impair sequence learning but do impair conditional visuomotor learning in monkeys. Neuropsychologia 38:1054-1072.

Olszewski J (1952) The thalamus of Macaca mulatta. An atlas for use with the stereotaxic instrument. Basel: Karger.

Orioli PJ, Strick PL (1989) Cerebellar connections with the motor cortex 
and the arcuate premotor area: analysis employing retrograde transneuronal transport of WGA-HRP. J Comp Neurol 288:612-626.

Pascual-Leone A, Grafman J, Clark K, Stewart M, Massaquoi S, Lou JS, Hallett M (1993) Procedural learning in Parkinson's disease and cerebellar degeneration. Ann Neurol 34:594-602.

Pascual-Leone A, Grafman J, Hallett M (1995) Procedural learning and prefrontal cortex. Ann NY Acad Sci 769:61-70.

Pascual-Leone A, Wassermann EM, Grafman J, Hallett M (1996) The role of the dorsolateral prefrontal cortex in implicit procedural learning. Exp Brain Res 107:479-485.

Passingham R (1993) The frontal lobes and voluntary action. Oxford: Oxford UP.

Percheron G (1977) The thalamic territory of cerebellar afferents and the lateral region of the thalamus of the macaque in stereotaxic ventricular coordinates. J Hirnforsch 18:375-400.

Percheron G, Francois C, Talbi B, Yelnik J, Fenelon G (1996) The primate motor thalamus. Brain Res Rev 22:93-181.

Petersen SE, Fox PT, Posner MI, Mintun M, Raichle ME (1988) Positron emission tomographic studies of the cortical anatomy of single-word processing. Nature 331:585-589.

Petrides M (1995) Impairments on nonspatial self-ordered and externally ordered working memory tasks after lesions of the mid-dorsal part of the lateral frontal cortex in the monkey. J Neurosci 15:359-375.

Petrides M, Milner B (1982) Deficits on subject-ordered tasks after frontal- and temporal-lobe lesions in man. Neuropsychologia 20:249-262.

Raichle ME, Fiez JA, Videen TO, MacLeod AM, Pardo JV, Fox PT, Petersen SE (1994) Practice-related changes in human brain functional anatomy during nonmotor learning. Cereb Cortex 4:8-26.

Rosen GD, Harry JD (1990) Brain volume estimation from serial section measurements: a comparison of methodologies. J Neurosci Methods 35:115-124.

Rosene DL, Mesulam MM (1978) Fixation variables in horseradish peroxidase neurohistochemistry. I. The effects of fixation time and perfusion procedures upon enzyme activity. J Histochem Cytochem 26:28-39.

Rosene DL, Roy NJ, Davis BJ (1986) A cryoprotection method that facilitates cutting sections of whole monkey brains for histological and histochemical processing without freezing artifact. J Histochem Cytochem 34:1301-1315.

Rouiller EM, Liang F, Babalian A, Moret V, Wiesendanger M (1994) Cerebellothalamocortical and pallidothalamocortical projections to the primary and supplementary motor cortical areas: a multiple tracing study in macaque monkeys. J Comp Neurol 345:185-231.

Rushworth MF, Nixon PD, Eacott MJ, Passingham R (1997) Ventral prefrontal cortex is not essential for working memory. J Neurosci 17:4829-4838.

Sakai K, Hikosaka O, Miyauchi S, Takino R, Sasaki Y, Putz B (1998) Transition of brain activation from frontal to parietal areas in visuomotor sequence learning. J Neurosci 18:1827-1840.

Sakai ST, Inase M, Tanji J (1996) Comparison of cerebellothalamic and pallidothalamic projections in the monkey (Macaca fuscata): a double anterograde labeling study. J Comp Neurol 368:215-228.

Sasaki K, Jinnai K, Gemba H, Hashimoto S, Mizuno N (1979) Projection of the cerebellar dentate nucleus onto the frontal association cortex in monkeys. Exp Brain Res 37:193-198.

Schell GR, Strick PL (1984) The origin of thalamic inputs to the arcuate premotor and supplementary motor areas. J Neurosci 4:539-560.

Schmahmann JD (1991) An emerging concept. The cerebellar contribution to higher function. Arch Neurol 48:1178-1187.
Schmahmann JD (1997) Rediscovery of an early concept. Int Rev Neurobiol 41:3-27.

Schmahmann JD, Pandya DN (1995) Prefrontal cortex projections to the basilar pons in rhesus monkey: implications for the cerebellar contributions to higher function. Neurosci Lett 199:175-178.

Schmahmann JD, Pandya DN (1997a) Anatomic organization of the basilar pontine projections from prefrontal cortices in rhesus monkey. J Neurosci 17:438-458.

Schmahmann JD, Pandya DN (1997b) The cerebrocerebellar system. Int Rev Neurobiol 41:31-60.

Schmahmann JD, Sherman JC (1998) The cerebellar cognitive affective syndrome. Brain 121:561-579.

Shelton RC, Weinberger DR (1986) X-ray computerized tomography studies in schizophrenia: a review and synthesis. In: Handbook of schizophrenia (Nasrallah HA, Weinberger DR, eds), pp 207-250. New York: Elsevier.

Snider SR (1982) Cerebellar pathology in schizophrenia: cause or consequence? Neurosci Biobehav Rev 6:47-53.

Stanton G (1980) Topographical organization of ascending cerebellar projections from the dentate and interposed nuclei in Macaca mulatta: an anterograde degeneration study. J Comp Neurol 190:699-731.

Stanton GB, Orr A (1985) [3H]Choline labeling of cerebellothalamic neurons with observations on the cerebello-thalamo-parietal pathway in cats. Brain Res 335:237-243.

Strick PL, Card JP (1992) Transneuronal mapping of neural circuits with alpha herpesviruses. In: Experimental neuroanatomy: a practical approach (Bolam JP, ed), pp 81-101. Oxford: Oxford UP.

Strick PL, Hoover JE, Mushiake H (1993) Evidence for "output channels" in the basal ganglia and cerebellum. In: Role of the cerebellum and basal ganglia in voluntary movement (Mano N, Hamada I, DeLong MR, eds), pp 171-180. Amsterdam: Elsevier.

Tolbert DL, Bantli H, Bloedel JR (1978) Multiple branching of cerebellar efferent projections in cats. Exp Brain Res 31:305-316.

Vilensky JA, van Hoesen GW (1981) Corticopontine projections from the cingulate cortex in the rhesus monkey. Brain Res 205:391-395.

Volkow ND (1992) Low cerebellar metabolism in medicated patients with chronic schizophrenia. Am J Psychiatry 149:686-688.

Walker AE (1940) A cytoarchitectural study of the prefrontal area of the macaque monkey. J Comp Neurol 73:59-86.

Weinberger DR, Torrey EF, Wyatt RJ (1979) Cerebellar atrophy in chronic schizophrenia. Lancet 1:718-719.

Wiesendanger R, Wiesendanger M (1985a) The thalamic connections with medial area 6 (supplementary motor cortex) in the monkey (Macaca fascicularis). Exp Brain Res 59:91-104.

Wiesendanger R, Wiesendanger M (1985b) Cerebello-cortical linkage in the monkey as revealed by transcellular labeling with the lectin wheat germ agglutinin conjugated to the marker horseradish peroxidase. Exp Brain Res 59:105-117.

Wilson FA, O'Scalaidhe SP, Goldman-Rakic PS (1994) Dissociation of object and spatial processing domains in primate prefrontal cortex. Science 260:1995-1997.

Yamamoto T, Yoshida K, Yoshikawa Y, Kishimoto Y, Oka H (1992) The medial dorsal nucleus is one of the thalamic relays of the cerebellocerebral response to the frontal association cortex in the monkey: horseradish peroxidase and fluorescent dye double staining study. Brain Res 579:315-320.

Yates WR, Jacoby CG, Andreasen NC (1987) Cerebellar atrophy in schizophrenia and affective disorder. Am J Psychiatry 144:465-467.

Zemanick MC, Strick PL, Dix RD (1991) Transneuronal transport of herpes simplex virus type 1 in the primate motor system: transport direction is strain dependent. Proc Natl Acad Sci USA 88:8048-8051. 